\title{
Managing Flap Vortices via Separation Control
}

\author{
David Greenblatt ${ }^{1}$ \\ Flow Physics and Control Branch, NASA Langley Research Center, Hampton VA 23681-2199
}

A pilot study was conducted on a flapped semi-span model to investigate the concept and viability of near-wake vortex management by means of boundary layer separation control. Passive control was achieved using a simple fairing and active control was achieved via zero mass-flux blowing slots. Vortex sheet strength, estimated by integrating surface pressures, was used to predict vortex characteristics based on inviscid rollup relations and vortices trailing the flaps were mapped using a seven-hole probe. Separation control was found to have a marked effect on vortex location, strength, tangential velocity, axial velocity and size over a wide range of angles of attack and control conditions. In general, the vortex trends were well predicted by the inviscid rollup relations. Manipulation of the separated flow near the flap edges exerted significant control over either outboard or inboard edge vortices while producing small lift and moment excursions. Unsteady surface pressures indicated that dynamic separation and attachment control can be exploited to perturb vortices at wavelengths shorter than a typical wingspan. In summary, separation control has the potential for application to time-independent or time-dependent wake alleviation schemes, where the latter can be deployed to minimize adverse effects on ride-quality and dynamic structural loading.

\footnotetext{
${ }^{1}$ NRC Research Associate, Flow Physics \& Control Branch, Mail Stop 170, Senior Member.
} 


\section{Nomenclature}

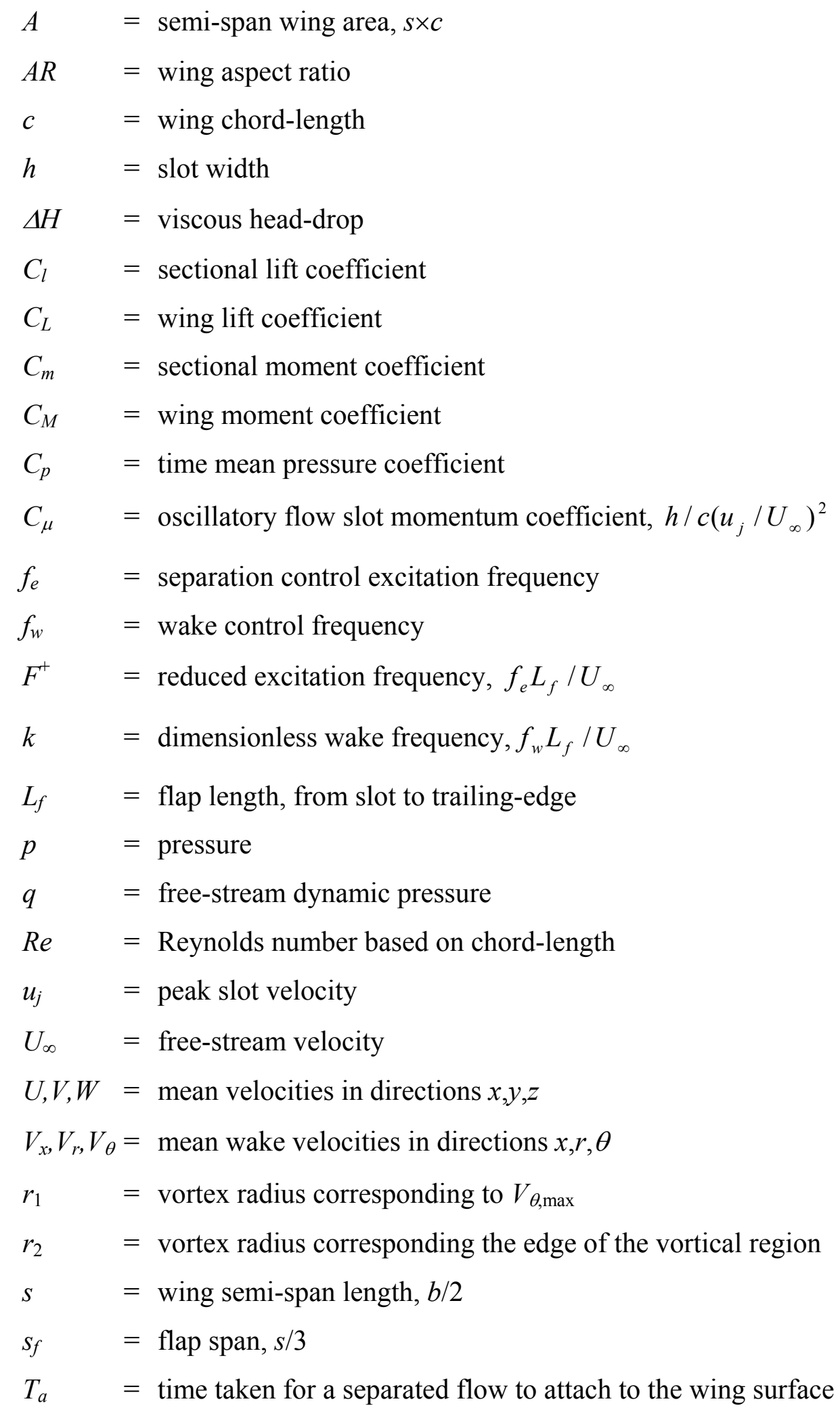




$$
\begin{array}{ll}
T_{s} & =\text { time taken for an attached flow to separate from the wing surface } \\
x, y, z & =\text { coordinates measured from model leading-edge and root } \\
y^{\prime} & =\text { coordinate measured from the tip, } s-y \\
y_{0}^{\prime} & =\text { coordinate measured from the outboard flap, }{ }^{2} / 3-y \\
(\bar{y}, \bar{z}) & =\text { vortex centroid } \\
\alpha & =\text { angle of attack } \\
\alpha_{s} & =\text { static stall angle } \\
\delta & =\text { flap deflection angle } \\
\Gamma & =\text { wing bound circulation } \\
\Gamma^{\prime} & =\text { vortex strength } \\
\gamma & =\text { wing vortex sheet strength, } d \Gamma / d y \\
\omega_{x} & =\text { streamwise vorticity } \\
<> & =\text { phase-averaged quantity }
\end{array}
$$

$\underline{\text { Subscripts }}$

$$
\begin{aligned}
i & =\text { inboard } \\
o & =\text { outboard } \\
t & =\text { tip } \\
t e & =\text { trailing-edge }
\end{aligned}
$$

$\underline{\text { Superscripts }}$

* $\quad=$ with separation control

$\wedge \quad=$ non-dimensionalization w.r.t. $U_{\infty}, b, c$ 


\section{Introduction}

\section{A. Background}

The hazard posed by powerful vortices trailing large commercial airliners has long been the subject of extensive research. ${ }^{1,2,3}$ Aircraft that encounter or penetrate vortices can experience severe loads or rolling moments, depending on their size as well as their location and orientation with respect to the vortices. This hazard is particularly severe near airports where planes fly in close proximity and where the relatively low flight speeds result in enhanced vortex strength. Although the vortices are usually transported away by self-induction or by atmospheric currents, this is not always the case and several accidents have been attributed to vortex encounters in recent decades. ${ }^{4}$ Under present flight rules, the delays due to separation distances are often larger than those dictated by other factors, and thus add to airport delays and congestion. ${ }^{5}$

There has long been an urgent need to destroy vortices or cause them to dissipate to some acceptable level. Methods employing "turbulence injection," by means of spoilers, splines, vortex generators, and fins generally produce insufficient far-field alleviation and often significantly increase drag. ${ }^{6,7}$ An alternative approach is to somehow exploit unstable growth mechanisms, such that vortices ultimately interact, pinch-off, and degenerate into harmless small-scale turbulence. The origin of this concept is based on wake instability observations ${ }^{8}$ that were subsequently analyzed and explained in terms of mutual induction. ${ }^{9}$ Two main approaches are proffered: time-invariant methods and time-dependent methods. (These are also referred to as passive and active methods, but the present terminology is adopted to avoid confusion with boundary layer separation control methods discussed below.) Time-invariant methods rely on modifying the span loading to establish two or more pairs of opposite-signed counter-rotating vortices and allow naturally arising instabilities to bring about their linking and mutual destruction. Some examples include appropriately configuring inboard flap vortices, ${ }^{10}$ employing multiple differentially deflected flaps ${ }^{11,12}$ or employing triangular outboard flaps. ${ }^{13}$ It has been shown that the relative flap-to-tip vortex strength plays a decisive role in the evolution of the wake vortices. ${ }^{13}$ Time-dependent methods that actively force the breakup of vortices are realized, for example, by differentially deflecting inboard and outboard control surfaces ("sloshing" of the lift distribution). ${ }^{14,15}$ This method was tested in a towing tank, ${ }^{16}$ where measured amplification rates agreed qualitatively with theoretical predictions. Recently, a similar approach was pursued with a view to exploiting the multiple vortex growth mechanisms created by an airplane on 
approach with flaps-down. ${ }^{4}$ Numerical simulations and towing tank experiments showed a breakup of the trailing vortices more rapidly than a comparable excitation of the Crow instability on a single pair of vortices. Despite their inherent appeal, active methods must address issues such as "ride quality, dynamic-load effects on the structure, and the ability to maintain control authority during operation". ${ }^{17}$

\section{B. Flap Vortices}

"Flaps-down" is a pseudonym for complex "high-lift systems" deployed by all large airlines to achieve the low speeds required for take-off and landing. ${ }^{18,19}$ Vortices shed from the flap edges are not only significant; they apparently dominate the ensuing wake structure. For example, at typical approach angles of attack $(\sim 5 \mathrm{deg}),{ }^{18}$ the flap vortex strength exceeds that of the wing tip vortex and the two vortices usually merge at a number of span-lengths downstream. ${ }^{20}$ In configurations with both inboard and outboard flaps, common amongst large airliners, the outboard flap vortex dominates the vortex field ${ }^{21}$ while the inboard vortex apparently remains significant yet separate from the outboard-wing tip combination for a considerable distance downstream. A stability analysis of such a two-vortex pair, ${ }^{22}$ revealed short wavelength instabilities with growth-rates up to 2 times larger than the Crow instability. The unstable wavelengths depend on vortex-core size, spacing and strength. In addition, a transient growth mechanism was identified that can amplify an initial disturbance by a factor of 10 to 15 in one-fifth of the time required for the same growth due to instability at the same wavelength. It is evident, therefore, that the characteristics of the flap-edge vortices must play an important role in any successful wake vortex alleviation strategy.

\section{Boundary Layer Separation Control}

While high-lift systems are effective in delivering the required $C_{L}$ for landing, they are aerodynamically inefficient due to flow separation on flaps and in the wing-flap cove region. ${ }^{23}$ Although separated flow is generally associated with aerodynamic inefficiency, it may also be viewed as a resource that is a by-product of the high-lift system. This resource can be harnessed by enhancing flow attachment to the surfaces, for example by means of passive devices ${ }^{24}$ or low-energy active perturbations. ${ }^{25}$ The control of separation directly affects lift, or bound circulation $\Gamma$, and therefore has the potential to modify the vortex sheet strength (or shed vorticity) $\gamma=d \Gamma / d y$. Since the vortex sheet on a flapped wing rolls up into multiple distinct 
vortices, boundary layer separation control emerges as a strong candidate for directly controlling, or managing, the individual vortices. Moreover, local control of separation, e.g. over some fraction of the flap-span, has the potential for locally modifying $\gamma$, thereby exerting control over individual vortices while simultaneously minimizing lift excursions. Presently, however, little is known of the efficacy of separation control in the highly three-dimensional flap-edge region.

Active separation control methods, in general, provide greater flexibility in that they have greater authority and can control the degree of boundary layer separation. Furthermore, separation and attachment can be controlled dynamically. ${ }^{26}$ Therefore, if separation control can be shown to be a feasible means of managing trailing vortices, then dynamic separation and attachment can be further exploited to achieve this in a time-dependent manner. Dynamic separation control can then be employed for directly exciting wake instabilities.

\section{Objective \& Scope}

The concept and viability of vortex management via separation control was investigated by conducting a pilot study involving a semi-span wing model, tested in the Basic Aerodynamics Research Tunnel (BART) at the NASA Langley Research Center. Details of the wing design and setup are provided in section II. The wing is equipped with three flaps, each with its own excitation slot that was configured to produce zero net mass-flux excitation. Span loading was estimated using surface pressure ports and dynamic response of the flow was ascertained by means of unsteady pressure ports. Empirical span-loading data were used together with inviscid vortex rollup relations (section III.A; IV) to predict the near-field vortex characteristics such as location, strength, peak velocities, and vortex size. Flow field measurements using a seven-hole probe were performed in the near-wake of the wing and the vortex characteristics were compared to the inviscid rollup predictions (section III.A; IV).

This pilot study presently does not address the intermediate or far-field vortex structure. The primary objective was to assess the use of separation control for generating boundary conditions that are consistent with those believed to be effective for time-invariant and time-dependent vortex alleviation strategies. A secondary objective was to assess authority over the vortex while simultaneously minimizing lift and moment excursions. A further secondary objective was to conduct a preliminary assessment of the efficacy of dynamic separation and attachment control as a means for dynamically perturbing vortices. 


\section{Experimental Setup}

\section{A. Semi-Span Model}

Experiments were performed on a rectangular planform semi-span NACA 0015 model wing of aspect ratio $A R=4$ (semi-span $s=609.6 \mathrm{~mm}$, chord $c=304.8 \mathrm{~mm}$ ) cantilevered off the wall of a low-speed wind tunnel (see figs. 1 for coordinate systems) at 500,000 $\leq R e \leq 1,000,000$. The model has a main element and three simple flaps (inboard, outboard, and tip) of equal span $\left(s_{f}=S / 3\right)$, with the hingeline at the $70 \%$ chord. Each flap is independently adjustable through a range of $10^{\circ}$ (upwards) to $40^{\circ}$ (downwards) with indexed settings in $10^{\circ}$ increments, denoted $\left(\delta_{i}, \delta_{o}, \delta_{t}\right)$. Flap angles are maintained using brackets between the main element and flaps that are flush with the wing lower surface. The model has a blowing slot at the shoulder of each flap, each with a width of $0.76 \mathrm{~mm}$. (The main element has an additional leading-edge slot with a width of $0.5 \mathrm{~mm}$ that was not used in this study.) The model was constructed from aluminum, apart from the slot edges that were constructed from stainless steel in order to maintain a $0.25 \mathrm{~mm}$ edge. The wing tip plate was square and set to be flush with the edge of the tip flap.

\section{B. Types of Control}

The main element is effectively hollow, apart from necessary internal structure, and acts as a plenum for the various slots on the wing surface. It incorporates a main spar that includes three removable internal, sealed partitions and an upper cover plate. Zero mass-flux perturbations are introduced via two voice-coil type actuators that are connected to the sub-plenums via manifolds. The resulting sub-plenums are in fluidic communication with an adjacent flap-shoulder slot which produces the perturbations in the reduced frequency range $0.4 \leq F^{+} \leq 3$ with $C_{\mu} \leq 1.5 \%$, known to be effective for two-dimensional separation control. ${ }^{25}$ The uncertainty in the perturbation amplitude was estimated at $\Delta C_{\mu} / C_{\mu} \leq 20 \%$. In addition to the active flow control setup described above, passive control was exerted by placing a fairing over the slot between the main element and flap upper surface. This eliminated the small backward facing step introduced by the slot, thereby forming a smooth transition between the main element and flap.

\section{Measurement Techniques}

The model is further equipped with 165 static pressure ports arranged in a perpendicular spanwise and chordwise grid. The spanwise ports are located at the chordwise locations 
$x / c=5 / 100,3 / 10,77 / 100$, and 1 , and are grouped more closely near the tip. The chordwise ports are located at nominal spanwise locations: $y / s=1 / 6,1 / 2,5 / 6$ and 99/100, and are grouped more closely near the leading-edge, while the flaps are equipped with additional ports. Surface pressures were integrated in order to compute aerodynamic coefficients and estimates of pressures within the grid were obtained using a three-dimensional interpolation method. The model is also equipped with nine dynamic pressure transducers on the wing upper surface. Slot velocities were calibrated using a hot-wire anemometer and actuator performance was monitored using unsteady transducers mounted within the sub-plenums.

Wing static pressures were measured using a high-speed pressure scanner and unsteady pressures were measured by means of piezoresistive unsteady pressure transducers. The main source of error in the pressure measurements was due to precision, with $C_{p} \leq \pm 0.02$, based on $95 \%$ confidence intervals. A $1.6 \mathrm{~mm}$ diameter seven-hole probe, with accuracy better than $1 \%$ on the velocity magnitude and 0.5 degrees on the flow angles, was used to make wake measurements at $x / c=2$.

\section{Data Reduction Methods}

\section{A. Control Predictions using Inviscid Rollup Relations}

Predicting the effect of separation control on flap vortex characteristics was achieved using the method of Betz, ${ }^{27}$ in the form developed by Donaldson et al. ${ }^{28}$ Betz's method does not explicitly treat the rollup mechanism, but rather employs three conservation relations between the span-loading $\Gamma(y)$ and the rolling-up vortex $\Gamma^{\prime}(r)$. Betz employed the conservation of vorticity (see eqn. 2 below), and also postulated that the first and second moments of vorticity are conserved (see eqns. 1 and 3 below). Despite the relative simplicity of the method, it predicts flap vortex details that are in surprisingly good agreement with aircraft-wake wing tip vortices. ${ }^{28}$

Implementation of the method presented a difficulty due to the dearth of theoretical or computational methods capable of accurately predicting the effects of zero-efflux perturbations. In order to circumvent this problem, empirical data for $\gamma(y)=\Gamma(y) / d y$ was obtained by integrating wing surface pressures (see section II.C). To illustrate the application of the method consider the lift distributions that results from a deflection of the adjacent inboard and outboard flaps, without separation control (baseline case) and with control applied along the length of the flap (controlled case), shown in the top half of fig. 2. Separation control brings about an 
approximately uniform increase in lift (or circulation) along the extent of the flap and, consequently a substantial change to $\chi(y)$ in the vicinity if the flap edge. The lines are polynomial least squares curves, fitted to data points in the vicinity of the flap-edges. The net wing lift increase observed is generally undesirable from the perspective of vortex management (section I.A), but this example is used merely for the purposes of introducing and illustrating the method. Minimization of lift excursions is addressed in section IV.

The lower part of the figure shows the theoretically predicted rolled-up vortices in the socalled Trefftz plane, which is defined as the plane behind the wing that is perpendicular to the direction of, and moves with, the free-stream. For relatively complex wing-load distributions, such as that shown in fig. 2, Donaldson et al. ${ }^{28}$ showed that circulation becomes multi-valued during the rollup calculation and thus a single vortex rollup is not physically possible. They assumed that the vorticity shed between adjacent local $|d \Gamma / d y|$ minima rolls-up into individual vortices and that the local shed vorticity peak between the adjacent minima $\left(|d \Gamma / d y|_{m}\right)$, located at $y=y_{m}$, progresses into the center of the vortex. Using these criteria, the method predicts three distinct vortices in the Trefftz plane (fig. 2): at the wing tip (A), flap-edge (B) and wing-wall junction $(\mathrm{C})$. These predictions are consistent with observations, at least in the near field considered here $(x / c \leq 2)$. The relatively low pressures at the wing tip result from the wing tip vortex being partially rolled-up on the upper surface. Without further approximation, this precludes the application of rollup relations to the tip vortex.

Applying the method to the outboard flap vortex (B) for the uncontrolled case, the vorticity between adjacent $|d \Gamma / d y|$ minima $y_{A}$ and $y_{B}$ rolls-up into a vortex located at the centroid defined by:

$$
\bar{y}_{B} \int_{y_{A}}^{y_{B}} \frac{d \Gamma(y)}{d y} d y=\int_{y_{A}}^{y_{B}} y \frac{d \Gamma(y)}{d y} d y
$$

In addition, the remaining invariants described above can be written as:

$$
-\int_{y_{1}}^{y_{2}} \frac{d \Gamma(y)}{d y} d y=\int_{0}^{r_{B}} \frac{d \Gamma_{B}^{\prime}(r)}{d r} d r
$$

and

$$
-\int_{y_{1}}^{y_{2}}\left(y-\bar{y}_{12}\right)^{2} \frac{d \Gamma(y)}{d y} d y=\int_{0}^{r_{B}} r^{2} \frac{d \Gamma_{B}^{\prime}(r)}{d r} d r
$$


If we choose $y_{1}$ and $y_{2}$ to be equidistant from the centroid of shed vorticity, from eqn. 2 we can write

$$
\Gamma_{B}^{\prime}=\int_{y_{A}}^{y_{B}} \frac{d \Gamma}{d y} d y=\Gamma\left(y_{A}\right)-\Gamma\left(y_{B}\right),
$$

where the centroid, from eqn. 2 , is located at

$$
\bar{y}_{B}=\frac{1}{\Gamma_{B}^{\prime}} \int_{y_{A}}^{y_{B}} y \frac{d \Gamma}{d y} d y .
$$

and the radius at which the tangential velocity blends with the point vortex field (outer core radius), ${ }^{2}$ from eqn. 3 , is:

$$
r_{2 B}=\frac{y_{B}-y_{A}}{2}
$$

Finally, using the equation for an inviscid vortex, and a relation similar to that of eqn. 3 , the tangential velocity at the center of the vortex is:

$$
V_{\theta B}(0)=-\frac{1}{\pi}\left(\frac{d \Gamma}{d y}\right)_{y=y_{m B}}
$$

The relations expressed in equations (4) to (7) provide four basic characteristics of the baseline rolled-up vortex. An identical procedure is applied to the control case.

Simplifying assumptions associated with the above method, ${ }^{37,38}$ are well known. Nevertheless, when applying the method to a flow control problem, the limitations become less important when comparing changes, e.g. between baseline and controlled states: $\Delta \bar{y}=\bar{y}^{*}-\bar{y}$, $V_{\theta}^{*}(0) / V_{\theta}(0), \Gamma^{\prime *} / \Gamma^{\prime}$, and $r_{2}^{*} / r_{2}$. Furthermore, given the relative simplicity and rapidity of span-loading measurements versus wake-surveys, the method is particularly useful for ascertaining trends.

\section{B. Wake Measurements}

All wake measurements were performed in a plane at $x / c=2$, by means of a seven-hole probe, yielding $(U, V, W)$ as a function of $(y, z)$. Streamwise vorticity was calculated according to:

$$
\omega_{x}=\partial W / \partial y-\partial V / \partial z
$$

using central differences. Vortex strength in the wake and the vortex centroid were determined by means of the standard definitions: 


$$
\Gamma_{w}=\int \omega_{x} d A
$$

and

$$
\left(\bar{y}_{w}, \bar{z}_{w}\right)=\frac{1}{\Gamma_{w}} \int(y, z) \omega_{x} d A
$$

where the integration regions were chosen such that $\omega_{x}<<\omega_{x, \max }$ at the boundaries.

The tangential velocity $\left(V_{\theta}\right)$ and radial coordinate $(r)$ were determined from the in-plane velocity components $(V, W)$ and $(y, z)$ coordinates relative to the vortex centroid respectively. This allowed direct determination of the peak tangential velocity $V_{\theta, \max }$ and the corresponding inner core radius $\left(r_{1}\right)$, but scatter and asymmetry precluded accurate measurement of $r_{2}$. Recall from section III.A, however, that the Donaldson-Betz method predicts a finite centerline peak velocity $V_{d}(0)$, thus $r_{1}=0$.

\section{Discussion of Results}

A preliminary assessment of the symmetric wing (no flap deflections) was conducted at $R e=500,000$ and $R e=1,000,000$. Surface $C_{p}$ differences for the two Reynolds numbers were small because the leading-edge slot effectively tripped the boundary layer and the sharp square wing tip fixed separation of the tip flow at the lower wing tip edge. The wing stalled inboard, as expected, at $\alpha=14^{\circ}$. Pressure measurements on the model, including the region near the wing tip $(y / s>0.97)$, were consistent with data of other investigations ${ }^{30,31}$ that were conducted on models without flaps or slots and at higher Reynolds numbers $(\operatorname{Re} 2,000,000)$. It was concluded that the flap slots did not have a noticeable effect on the details of the tip vortex rollup or span loading. Moreover, the favorable comparison also validated the pressure interpolation scheme mentioned in section II.C.

\section{A. Inboard \& Outboard Flap Deflection}

The first configuration considered here was the deflection of adjacent inboard and outboard flaps $\left(\delta_{i}, \delta_{o}, \delta_{t}\right)=\left(20^{\circ}, 20^{\circ}, 0^{\circ}\right)$, discussed in section III.A, where zero mass-flux excitation was introduced along the length of the flapped section. Lift coefficient data presented in fig. 3a and $3 \mathrm{~b}$ are for the baseline case as well as control applied at two amplitudes, at an inboard location $(y / s=1 / 6)$ and for the wing respectively. As expected, the effect of control inboard (fig. 3a), where three-dimensional effects are negligible, is similar to that observed on airfoils. ${ }^{25}$ At 
relatively low amplitude $\left(C_{\mu}=0.21 \%\right)$, control is effective at $\alpha<0^{\circ}$ but its effectiveness gradually diminishes as $\alpha$ approaches stall $\left(\alpha_{s} \approx 12^{\circ}\right)$. The overall effect of separation control on $C_{L}$ at both amplitudes is qualitatively similar to that inboard, but the differences between baseline and control are smaller. This is because separation control is only effective over the flapped fraction of the span, while lift over the remainder of the span towards the tip is not significantly affected (e.g. fig. 2). Nevertheless, separation control is effective across the entire flap-span and trailingedge pressure recovery ( $C_{p, t}$; not shown) shows a nearly uniform change across the flap-span.

The experimentally determined span-loading (e.g. fig. 2) was used as input to the rollup relations (eqns. 1-7), to predict the effect of separation control on the four basic characteristics of the flap vortex for the baseline and two control cases discussed above. The data are shown in dimensionless form as a function of $\alpha$ (figs. $4 \mathrm{a}-4 \mathrm{~d}$ ). In general, the predictions indicate that separation control strengthens the vortex (fig. 4a), moves the centroid outboard (fig. 4b), increases the peak velocity (fig $4 \mathrm{c}$ ) and reduces the vortex size (fig. $4 \mathrm{~d}$ ). The extent to which vortex strength and peak velocity are controlled depends to some extent on the degree of separation control. At low $\alpha$ significant authority is achieved, but control over vortex strength and peak velocity diminishes as the wing approaches stall $\left(\alpha_{s} \approx 12^{\circ}\right)$. Nevertheless, significant authority is exerted over the centroid location and vortex size for a wide range of $\alpha$ up to stall. This is true for both low and high amplitude control, even when the effect on wing lift is small.

Control of an initially separated flow affects the aerodynamic coefficient in different ways, depending on the angle of attack (or flap deflection). At low angles of attack, the flow is seen to fully attach when some threshold perturbation level $\left(C_{\mu}\right)$ is exceeded. At higher angles of attack, a coefficient such as $C_{L}$ varies gradually, approximately logarithmically with $C_{\mu}$. These effects are illustrated with respect to relatively low and high angles $\left(\alpha=0^{\circ}\right.$ and $\left.8^{\circ}\right)$, where two different forcing frequencies are employed at the higher angle for illustrative purposes (fig. 5). At $\alpha=0^{\circ}$, relatively large changes in the aerodynamic coefficients are evident at $C_{\mu} \approx 0.15 \%$ and increasing the forcing amplitude thereafter has little effect. These effects are reflected to some degree in the control authority over the basic vortex characteristics (figs. 6b-6d) where changes are relatively small and authority saturates at a relatively low forcing level. At $\alpha=8^{\circ}$ the effect on $C_{L}$ and hence vortex characteristics is more gradual. Also, the thicker separated shear layer represents a larger resource for control and hence the control authority over the vortex is greater. The same would be true at lower angles of attack with greater flap deflections. 


\section{B. Segmented Actuation \& Zonal Control}

Separation control for the purpose of performance improvement is generally applied over the entire span of a separated region, resulting in significant changes to aerodynamic indicators. Thus if separation control was to be deployed in a time-dependent manner, it could potentially result in significant force and moment oscillations. A similar problem exists where control surfaces are used to perturb vortices. ${ }^{15,17,34}$ We address this problem in the following manner: if perturbations are applied locally along some fraction or segment of the slot, it is possible that separation can be achieved over a finite zone of the flap. Then, in principle, the local vortex sheet $\gamma=d \Gamma / d y$ can be varied and hence control can be exerted over a specific vortex, leaving the remainder of the wake unchanged, with considerably smaller excursions in lift and moment. Applying control over different parts of the flap periodically can then, in principle, eliminate load oscillations while facilitating time-dependent control of the vortices by so-called "sloshing"15 of the lift distribution. This is similar to the methods that oscillate control surfaces, ${ }^{4,15}$ but with two important differences: (i) the flap is maintained at a fixed deflection, and (ii) control on a single flap is sufficient to perturb the vortex with minimal load variations. Static data are discussed in this section, while dynamic aspects of this approach are discussed in section IV.E.

Due to the dearth of separation control data available in a three-dimensional environment, applied over a fraction of the span, we digress slightly here to discuss some details. Consider the application of separation control over the inboard and outboard halves of the slot, where trailingedge pressures $\left(C_{P, t e}\right)$ corresponding to these two cases are shown in figs. $7 \mathrm{a}$ and $7 \mathrm{~b}$, respectively. $C_{P, t e}$ indicates the degree of pressure recovery and hence "control effectiveness". For these data, segmented actuation was achieved using the fairing (described in section II) to seal the part of the slot not being used. The net result is that active separation control applied on one half of the flap is accompanied by mild passive control on the other half. Control effectiveness clearly increases with increasing $C_{\mu}$ and this can also be seen with respect to the effect on wing $C_{L}$ and $C_{M}$ (fig. 8). Nevertheless, the changes in $C_{L}$ and $C_{M}$ are smaller than when the separation is controlled over the entire flap (cf. fig. 5). A comparison of figs. $7 \mathrm{a}$ and $7 \mathrm{~b}$ shows that outboard control is more efficient in attaching the flow, in the sense that smaller $C_{\mu}$ is required for a given pressure recovery. Outboard control is also more effective in that the extent over which the pressure recovers is larger even at smaller $C_{\mu}$. This is also true for passive control, where small 
changes in the aerodynamic coefficients occur $\left(\Delta C_{L}=0.02, \Delta C_{M}=0.003\right)$ with outboard passive control, while no effect is evident with inboard passive control.

The reason for these differences must somehow be related to the different three-dimensional environment of the two control scenarios. It is suggested here that outboard control is more efficient and effective because the flap-edge vortex aids in the transfer of high-momentum fluid to the surface from below the wing. Hence outboard separation control is the result of a combination of spanwise vortices produced by excitation of the free shear layer superimposed approximately orthogonally on the flap-edge vortex. In contrast, inboard control terminates at the wind tunnel wall-wing junction, where a horseshoe vortex forms, ${ }^{36}$ and no fluid can be drawn from the lower part of the wing. It is not clear whether the junction vortex increases or decreases separation control effectives.

The difference in span loading for inboard and outboard control is shown for the passive case (fig. 9a) and an active case (fig. 9b). The active case was selected such that both inboard and outboard control produce similar $C_{L}$ and $C_{M}$ (see filled symbols in fig. 8). The rollup relations predict a relatively small effect of passive control with the exception of the vortex centroid and size (figs. 10a to 10d). This is due to the relatively large influence on $C_{l}$ in the vicinity of the flap-edge exerted by the passive device (fig. 9a), despite the small overall change in lift (see fig. 8). Active outboard control exerts substantial authority over the all of the vortex characteristics because the vortex sheet is significantly altered in the region where the vortex rolls up (e.g. fig. 9b). Changes generally have a logarithmic dependence on $C_{\mu}$, with the exception of the vortex centroid and size, where authority saturates at $C_{\mu} \approx 0.15$. Small changes occur with the application of inboard control because alterations to the vortex sheet occur remotely from flap-edge vortex. The filled symbols in the figures correspond to cases of similar $C_{L}$ and $C_{M}$ (see fig. 8) and thus indicate the degree of control that can be exerted by oscillating between the two states in a quasisteady manner. Note that data corresponding to inboard active control is shifted due to the effect of the passive outboard fairing that was employed to seal the outboard part of the slot. The advantage of the active method over the passive one is clearly illustrated here. In principle, active control from different locations can be used to produce precisely the same lift and can exert substantial and varied control over the vortices. Passive methods, on the other hand, operate in a simple on-off manner, thus limiting control flexibility over lift and vortex characteristics. 
Seven-hole probe measurements at $x / c=2$ for passive and active control, corresponding to the span-loadings illustrated in figs. $9 \mathrm{a}$ and $9 \mathrm{~b}$ (filled symbols in figs. 8 and 10), are shown in figs. 11a-11d (vorticity and in-plane velocity) and 12a-12d (streamwise velocity). Changes to the vortex characteristics between inboard and outboard control, both passive and active, are compared with those calculated from the rollup relations in table 1. In general, the predictions of centroid movement and peak velocity ratio are good, while vortex strength and size ratio only show the correct trends. Both rollup relations and wake measurements show the surprising result that that passive control has a larger effect on the vortex centroid. This serves to emphasize the fact that controlling the vortex sheet-strength in the vicinity of the flap edge can have a large effect on the centroid without significant changes to the overall aerodynamic loads. The comparison in table 1 also serves to illustrate the limitations of the rollup method. For example, simple passive control increases the vortex strength by $23 \%$ where this is not evident from the $5 \%$ increase predicted from the span-loading. The main reason for the poorer predictions is that the method neglects viscous effects which become more important when dealing with the rollup of separated shear layers.

Separation control also brings about changes to the vortex axial velocity, on the order of $0.25 U_{\infty}$ (figs. 12a-12d). This can be explained qualitatively using Batchelor's ${ }^{32}$ analysis applied here to the flap vortex by considering a streamline which extends from upstream of the wing through the vortex centerline (also see ref. 33). The axial velocity on the centerline can then be written as:

$$
\frac{V_{x}(0)}{U_{\infty}}=\sqrt{1+\frac{\left[p_{\infty}-p(0)\right]-\rho g \Delta H}{\rho U_{\infty}^{2} / 2}}
$$

where the fist term in the quotient on the right hand side is the pressure drop in the vortex $\left[\propto\left(\Gamma / r_{1}\right)^{2}\right]^{33}$ and the second term is a head-drop representing viscous losses. Considering the increased circulation and decreased size associated with the controlled vortex (table 1), it is clear from eqn. 11 that separation control acts to increase the vortex centerline axial velocity. In addition, viscous losses in an attached boundary layer will be significantly less than those in a thicker separated shear layer. Thus control acts to further increase the centerline velocity by reducing the viscous head-drop. It is therefore a combination of increased pressure drop and decreased head-drop that are jointly responsible for the higher axial velocities. 
The rollup relations assume a flat vortex sheet and rollup and thus do not account for vertical centroid displacements. The overall displacements measured in the wake are shown in the $(y, z)$ map in fig. 13 and indicate that control also exerts an effect in the vertical $z$-direction. The passive and active control centroids represent data at similar $C_{L}$, while the "No control" and "Full flap control" cases correspond to $\Delta C_{L}=0.17$. Recall that active inboard control is accompanied by passive outboard control, and vice versa, due to the deployment of the fairing. The maps show that different mode shapes could conceivably be excited by time-dependent separation control, but in general this would introduce variation in overall lift. In principle, this could be overcome on a configuration that employs control on more than one flap, where different mode shapes could be excited using control on one flap while overall lift is maintained constant by control on a second flap.

\section{Outboard Flap Deflection}

\section{Full-Span Flap Control}

The second flap configuration considered was the deflection of the outboard flap alone: $\left(\delta_{i}, \delta_{o}, \delta_{t}\right)=\left(0^{\circ}, 20^{\circ}, 0^{\circ}\right)$. This resulted in a substantial counter-rotating inboard vortex in addition to the outboard vortex considered previously. Management of the counter-rotating inboard vortex is considered important due to its prevalence in many vortex alleviation strategies. ${ }^{10,13}$ With control applied along the span of the flap, wing aerodynamic coefficient excursions were qualitatively similar to those for the previous case but $50 \%$ smaller, consistent with the shorter flap-span. Nevertheless, control exerted considerable authority over $\gamma$ at the flap edges and low amplitude excitation $\left(C_{\mu}\right)$ was effective to higher angles of attack. Corresponding wake measurements are shown in figs. $14 \mathrm{a}, \mathrm{b}$ and $15 \mathrm{a}, \mathrm{b}$, with control at $C_{\mu}=1 \%$, and are compared with the rollup predictions in table 2. In general, the changes to the outboard vortex characteristics are of the same order as those for the combined inboard and outboard flap deflections (c.f. section IV.B and table 1), although greater authority is exerted over the vortex centroid and size. The reasonable prediction of the outboard vortex centroid is evidence that the inboard edge of the flap does not significantly affect the near-field rollup of the outboard flap. Rather, it is the local changes in $\gamma$ that dominate. It is encouraging to note that authority over the vortex is maintained despite the shorter flap and corresponding $50 \%$ smaller lift excursions. 
Changes to both inboard and outboard vortex strength, measured in the wake, are similar when each is referenced to its baseline value and thus the relative strength of the vortices remains constant for baseline and control. A comparison with the rollup relations shows that the inboard vortex trends are not as well predicted. This may be a further limitation of the rollup method, which historically was never validated for counter-rotating vortices. ${ }^{35}$ An additional anomaly associated with the inboard vortex is that the axial velocity decreases with the application of control. This is contrary to that observed for the outboard vortex and also contradicts conventional arguments, such as that presented in section IV.B.

\section{Segmented Actuation}

In an attempt to maintain vortex control authority while further minimizing lift and moment excursions, perturbations were introduced from inboard and outboard halves of the flap respectively. As expected, control for both of these cases resulted in relatively small overall changes to the aerodynamic indicators, e.g. for both outboard and inboard control: $\Delta C_{L} \leq 0.05$ and $\Delta C_{M} \leq 0.01$ over the full range of control amplitude (see fig. 16). Despite these small changes, separation is very effectively controlled, as can be seen by the pressure recoveries associated with both inboard and outboard perturbations and the associated different span-loadings (e.g. fig. 17). Thus significant control is applied locally to the vortex sheet and this manifests as effective authority over both inboard and outboard vortices.

It is believed that the increase in bound circulation (lift) that accompanies separation control in two-dimensional flows is "lost" to the vortices when control is applied near the flap edges. Less of this circulation is lost when control is applied remotely from the edges. Thus, control applied near flap edges has the potential for significant vortex control accompanied by a relatively small aerodynamic load changes.

Wake measurements are shown in figs. $18 \mathrm{a}$ and $18 \mathrm{~b}$ and overall comparison of the vortex characteristics are shown in tables $3 \mathrm{a}$ and $3 \mathrm{~b}$. It is evident that the application of control in the vicinity of the flap edges does not diminish authority over either the outboard vortex (table 3a) or the inboard vortex (table $3 b$ ). Thus the relative strengths of the vortices can be significantly varied with small changes to the aerodynamic loads. For example, the ratio of inboard to outboard vortex strength is varied from 0.55 (outboard control) to 0.87 (inboard control) with $\Delta C_{L} \approx 0.01$. Note that even with inboard control, the outboard vortex is stronger, although the 
peak inboard vorticity is more than double the outboard peak in this instance (figs. 18b). As in the case of full flap-span control, the rollup predictions are inferior for the inboard vortex.

\section{Dynamic Vortex Management}

One of the objectives of vortex management involves the direct excitation of instabilities in the wake, designed to reduce the time to their interaction and mutual destruction. Data presented in sections IV.B and $\mathrm{C}$ was indicative of quasi-steady perturbation, corresponding to excitation at arbitrarily long wavelengths. For purposes of this discussion, a distinction can be made between the separation control frequency $\left(f_{e}\right)$ and the wake perturbation frequency $\left(f_{w}\right)$. For wake alleviation strategies, instability wavelengths $\left(\lambda=U_{\infty} / f_{w}\right)$ are typically $\mathrm{O}(b)$ or larger, while separation control frequencies are $\mathrm{O}\left(U_{\infty} / L_{f}\right)$. Thus, for the semi-span model studied here, and indeed for almost all aircraft, $L_{f}<<b$, therefore $f_{w}<<f_{e}{ }^{*}$

In this section, an attempt is made to estimate $f_{w, \max }$ or, equivalently, the shortest wavelength $\left(\lambda_{\min }\right)$ for which full control authority is maintained. This depends directly on the time-scales characterizing dynamic separation and attachment $\left(T_{s}\right.$ and $\left.T_{a}\right)$ that are larger than the separation control time-scales $1 / f_{e}$, with $T_{s} \approx T_{a} \approx 16 L_{f} / U$ to $20 L_{f} / U$ on a generic two-dimensional flap. ${ }^{40,41}$ Based on these observations, full control authority cannot be achieved faster than $T_{s}+T_{a}$, alternatively:

$$
f_{w, \max } \leq \frac{1}{T_{s}+T_{a}}
$$

Defining $k=f_{w} L_{f} / U_{\infty}$ and $\xi=L_{f} / c$, the dimensionless wavelength can be expressed as:

$$
\lambda / b=\xi / k A R
$$

where $\lambda_{\min } / b=\xi / k_{\max } A R$ is estimated at $2.7 .^{40,41}$

Dynamic $C_{p}$ 's at the wing center-span were measured at $x / c=0.0,0.3,0.705$ (immediately downstream of the flap-shoulder slot) and 1.0 for $\left(\delta_{i}, \delta_{o}, \delta_{t}\right)=\left(0^{\circ}, 20^{\circ}, 0^{\circ}\right)$, where flap-span perturbations are driven in "burst-mode" at frequencies $f_{w}<f_{e}$. For illustrative purposes, $f_{w}=4 \mathrm{~Hz}$ is considered, where $f_{e}=210 \mathrm{~Hz}$ corresponds to $F^{+}=0.79$. When perturbations are initiated or terminated, the upper surface pressures respond as the boundary layer either attaches to, or detaches from, the surface (see phase-averaged leading-edge and trailing-edge dynamic $C_{p}$ data

*Perturbation of vortices at the separation control reduced frequency $F^{+}$, corresponding to $\lambda / b<<1$, was not considered here. ${ }^{39}$ 
in fig. 19). Minimum and maximum $C_{p}$ data points can be discerned, as indicated in figs. 19. The relatively large high frequency oscillations $\left(f_{e}\right)$ at the trailing-edge (and flap shoulder; not shown) are due to the coherent initiation, amplification and advection of the separation control vortices. These oscillations are much reduced at $x / c=0$ due to their being located remotely from the forcing slot.

Interpretation of the unsteady $C_{p}$ data is based on a detailed study of two-dimensional generic flap dynamic separation and attachment. ${ }^{40,41}$ When perturbations are initiated $(t=0)$, the streamlines initially deflect away from the flap surface, resulting in the observed drop in the trailing-edge pressure $\left(C_{p, \min }\right)$. Thereafter, fully attached flow is established over $T_{a} \approx 14 L_{f} f U$ consistent with ref. 40 . With the termination of perturbations, $(t=0.125 \mathrm{~s})$, a dynamic stall vortex is shed from the flap, as exemplified by the relatively large $C_{p}$ oscillation, whereafter fully separated flow is established over $T_{a} \approx 12 L_{f} f$, which is somewhat less than that of ref. 41 . Consequently, for the semi-span model studied here: $\lambda_{\min } / b \approx 2$. Trailing-edge $C_{p}$ 's show that the baseline-to-control excursions are exceeded when the actuators are driven in burst mode, due to $C_{p}$ overshoots that are associated with dynamic separation and control. It is thus reasonable to surmise that control authority over the vortex wielded by dynamic separation and attachment may exceed that measured under static conditions above (sections IV.A-IV.C).

Furthermore, the alternating dynamic deflection of the streamlines and shedding of a dynamic stall vortex can be used to perturb the wake at even shorter wavelengths. To illustrate this, consider maximum and minimum $C_{p}$ data as a function of $\lambda / b$ (eqn. 13 with $A R=4$ and $\xi=0.3$ ) for $x / c=1$ and 0 , respectively (figs. 20a and 20b). Also shown are the conditions where no control (baseline) is applied and the condition where control is applied in a "time-invariant" manner (no modulation). With increasing $f_{w}$ (decreasing $\lambda / b$ ), the trailing-edge control authority is maintained up to the highest frequency considered here, corresponding to $\lambda / b \approx 0.5$.

The leading-edge minimum and maximum $C_{p}$ data also exhibit overshoots, but only for $\lambda / b>3$ (see fig. 20b) and similar results were observed at $x / c=0.3$. The differences in pressure between controlled and baseline cases $\left(C_{p, \min }-C_{p, \max }\right)$ offer some indication of local lift fluctuations that exist between the attached and separated states. On the other hand, their mean values $1 / 2\left(C_{p, \min }+C_{p, \max }\right)$ are proportional to net local lift increase. Consequently, with increasing $f_{w}$, lift increases while lift oscillations decrease as can be seen by inspection in fig. 20b. This should be contrasted with the flap $C_{p}$ 's that are virtually independent of $f_{w}$. It may thus be conjectured that 
dynamic separation and attachment control can be deployed to attain significant short wavelength vortex perturbations with simultaneously diminishing wing load excursions.

\section{Concluding Remarks}

The concept and viability of managing vortices trailing wing flaps by means of active and passive separation control, was demonstrated experimentally. Separation control was found to have a marked effect on vortex location, strength, tangential velocity, axial velocity and size over a wide range of flap deflections, angles of attack and control conditions. In many instances the quantitative vortex characteristics were well predicted by the inviscid rollup relations. Separation control applied near the flap edges exerted significant control over either outboard or inboard edge vortices while producing relatively small lift and moment excursions. The large disparity between the scales characterizing dynamic separation control (fraction of flap chord) and those characterizing wake instabilities (multiple of wing-span), facilitated perturbation of the vortices from arbitrarily long wavelengths down to wavelengths less than a typical wingspan. The method is now in a position to be tested in a wind tunnel with a longer test section, a tow tank, or even on a light aircraft.

It is believed that this method will have significant appeal from an industry perspective due its retrofit potential with no impact on cruise (separation control devices are tucked away in the cove); low operating power requirements (separated flow instabilities are exploited); small lift oscillations when deployed in a dynamic manner; and significant flexibility (application to different high-lift systems or different flight conditions).

\section{Acknowledgments}

This work was performed while the author held a National Research Council-NASA Langley Research Center Associateship. The author wishes to thank W. L. Sellers III, A. E. Washburn, M. J. Walsh, L. P. Melton, L. N. Jenkins, D. H. Neuhart, J. C. Lin, G. S. Jones, S. A. Gorton, G. C. Greene, M. R. Khorrami, I. J. Wygnanski (University of Arizona) and H. M. Nagib (IIT, Chicago) for their active assistance and many fruitful discussions. The author also wishes to thank R. D. White, A. Barnes and R. L. Clark for their exceptional technical support.

\section{References}

1. Green, S. I., "Wing Tip Vortices," in "Fluid Vortices," Green, S. I. (ed.), Kluwer Academic Press, 1995, Ch. 1, pp. 1-33. 
2. Spalart, P. R., “Airplane Trailing Vortices," Annual Review of Fluid Mechanics, Vol. 30, 1998, pp. 107-138.

3. Rossow V. J. "Lift-Generated Vortex Wakes of Subsonic Transport Aircraft," Progress in Aerospace Sciences, Volume 35, Issue 6, 1999, pp. 507-660.

4. Crouch, J. D., Miller, G. D. and Spalart, P. R. "Active-Control System for Breakup of Airplane Trailing Vortices,” AIAA Journal, Vol. 39, No. 12, 2001, pp. 2374-2381.

5. Robinson, J. J., "A Simulation-Based Study of the Impact of Aircraft Wake Turbulence Weight Categories on Airport Capacity," CP-584, AGARD, 1996, pp. 22-1-22-15.

6. Dunham, Jr., R. E., "Unsuccessful Concepts For Aircraft Wake Vortex Minimization," Proceedings Wake Vortex Minimization Symposium, NASA, SP-409, 1977, pp. 221-250.

7. Rossow, V. J., "Prospects for Alleviation of Hazard Posed by Lift-Generated Wakes," Proceedings of the Aircraft Wake Vortices Conf., DOT/FAA/SD-92/1.1, 1991, pp. 22-1 - 2240.

8. Scorer R.S., "Natural Aerodynamics," Pergamon, New York, 1958.

9. Crow, S. C., "Stability theory for a pair of vortices," AIAA Journal, Vol. 8, 1970, pp. 21722179.

10. Rennich, S. C. and Lele, S. K., "Method for Accelerating the Destruction of Aircraft Wake Vortices," AIAA Journal of Aircraft, Vol. 36, No. 2, 1999, pp. 398-404.

11. Rossow, V. J. "Theoretical Study of Lift-Generated Vortex Wakes Designed to Avoid Rollup," AIAA Journal, Vol. 13, No. 4, 1975, pp. 476-484.

12. Cliffone, D. L. and Orloff, K. L., "Far Field Wake-Vortex Characteristics of Wings," AIAA Journal of Aircraft, Vol. 12, No. 5, 1975, pp. 464-470.

13. Ortega, J. M., Bristol R. L. and Savas, Ö., "Experimental Study of the Instability of UnequalStrength Counter-Rotating Vortex Pairs" J. Fluid Mech., Vol. 474, 2003, pp. 35-84.

14. Crow, S. C., "Panel Discussion," in Aircraft Wake Turbulence and Its Detection, edited by J. H. Olsen, A., Goldburg, and M. Rogers, 1971, Plenum Press, New York, pp. 580-582.

15. Crow, S. C. and Bate E. R., "Lifespan of Trailing Vortices in a Turbulent Atmosphere," Journal of Aircraft, Vol. 13, No 7, 1976, pp. 476-82.

16. Bilanin, A. J., and Widnall, S. E., "Aircraft Wake Dissipation by Sinusoidal Instability and Vortex Breakdown,” AIAA Paper 73-107, 1973.

17. Crouch, J. D., "Forcing the Breakup of Airplane Trailing Vortices," Conference on Capacity and Wake Vortices, Imperial College of Science, Technology and Medicine, London, England, September 2001.

18. Rudolph, P. K. C. "High-Lift Systems on Commercial Subsonic Airliners," NASA CR 4746, 1996.

19. van Dam, C. P., "The Aerodynamic Design of Multi-Element High-Lift Systems for Transport Airplanes," Progress in Aerospace Sciences, Volume 38, 2002, pp. 101-144.

20. de Bruin, A.C., Hegen, S.H., Rohne, P.B. and Spalart, P.R., "Flow Field Survey in the Trailing Vortex System Behind a Civil Aircraft Model at High Lift," AGARD-CP-584, 1996, pp. $25-1$ to 25.12 .

21. Bellastrada, C., Breitsamter, C. and Laschka, B, "Investigation of Turbulent Wake Vortex Originating From a Large Transport Aircraft in Landing Configuration," Proc. CEAS Aerospace Aerodynamics Research Conference, 2002, pp 31.1-31.10.

22. Crouch J. D., "Instability and transient growth for two trailing-vortex pairs," J. Fluid Mech., Vol. 350, 1997, pp. 311-330. 
23. Rumsey, C.L. and Ying, S.X., "Prediction of High Lift: Review of Present CFD Capability," Progress in Aerospace Sciences Vol. 38, Issue 2, 2002, pp. 145-180.

24. Lin, J.C., "Review of Research on Low-Profile Vortex Generators to Control Boundary-Layer Separation," Progress in Aerospace Sciences, Vol. 38, Issue. 4, 2002, pp. 389-420.

25. Greenblatt, D. and Wygnanski, I, "Control of Separation by Periodic Excitation," Progress in Aerospace Sciences, Volume 37, Issue 7, pp. 487-545, 2000.

26. Greenblatt, D., Nishri, B., Darabi, A. and Wygnanski, I., "Dynamic Stall Control by Periodic Excitation. Part 2: Mechanisms," AIAA Journal of Aircraft, Vol. 38, No. 3, 2001, pp. 439-447.

27. Betz, A., "Behavior of Vortex Systems," Zeit. für angewandte Math. und Mech., Vol. 12, No. 3, June 1932. See NACA TM 713, June 1933.

28. Donaldson, C duP., Snedeker, R. S. and Sullivan, R. D., "Calculation of Aircraft Wake Velocity Profiles and Comparison with Experimental Measurements," AIAA Journal of Aircraft, Vol. 11, No. 9, 1974, pp. 547-555.

29. Yates, J.E., "Calculation of Initial Vortex Roll-Up in Aircraft Wakes," AIAA Journal of Aircraft, Vol. 11, No. 7, 1974, pp. 397-400.

30. McAlister, K. W. and Takahashi, R. K. "NASA 0015 Wing Pressure and Trailing Vortex Measurements" NASA TP 3151 (AVSCOM Technical Report 91-A-003), November 1991.

31. Spivey, W. A. and Morehouse, G. G., "New Insights into the Design of Swept-Tip Rotor Blades," $26^{\text {th }}$ National Annual Forum Proceesdings of the American Helicopter Society, Washington, D.C., 1970.

32. Batchelor G.K., "Axial Flow in Trailing Line Vortices," J. Fluid Mech., Vol. 20, part 2, 1964, pp. 645-58.

33. Green, S. I., "Introduction to Vorticity," in "Fluid Vortices," Green, S. I. (ed.), Kluwer Academic Press, 1995, Ch. 10, pp. 427-470.

34. Chevalier H., "Flight Test Studies of the Formation and Dissipation of Trailing Vortices," Journal of Aircraft, Vol.10, No. 1, pp. 14-18.

35. Donaldson, C duP., Snedeker, R. S. and Sullivan, R. D., "Calculation of the Wakes of Three Transport Aircraft in Holding, Takeoff and Landing Configurations, and Comparison with Experimental Measurements” A.R.A.P. Report No. 190, 1973, AFSOR-TR-73-1594.

36. Simpson, R. L., "Junction Flows," Annual Review of Fluid Mechanics, Vol. 33, 2001, pp. 415-443.

37. Moore, D.W. and Saffman, P.G., "Axial Flow in Laminar Trailing Vortices," Proc. R. Soc., London Ser. A 333, 1973, pp. 491-508.

38. Widnall, S.E. "The Structure and Dynamics of Vortex Filaments," Annual Review of Fluid Mechanics, Vol. 7, 1975, pp. 141-165.

39. Greenblatt, D., Melton, L., Yao, C., Harris, J., "Active Control of a Wing Tip Vortex" AIAA Paper 2005-4851, 23rd AIAA Applied Aerodynamics Conference, Westin Harbour Castle, Toronto, Ontario, 6-9 June 2005.

40. Darabi, A. and Wygnanski, I., "Active management of naturally separated flow over a solid surface. Part 1. The forced reattachment process", J. Fluid Mech. Vol. 510, 2004, pp. 105129.

41. Darabi, A. and Wygnanski, I., "Active management of naturally separated flow over a solid surface. Part 2. The separation process", J. Fluid Mech. Vol. 510, 2004, pp. 131-144. 


\section{Tables}

Table 1. Comparison of vortex changes based on inviscid rollup relation predictions and nearwake measurements.

\begin{tabular}{|c|c|c|c|c|}
\hline & \multicolumn{2}{|c|}{ Partial Flap-Passive Control } & \multicolumn{2}{c|}{ Partial Flap-Active Control } \\
\hline & 7-hole Probe & Donaldson-Betz & 7-hole Probe & Donaldson-Betz \\
\hline$\Delta \bar{y} / s(\%)$ & 1.3 & 1.5 & 0.82 & 0.78 \\
\hline$\Gamma^{*} / \Gamma^{\prime}$ & 1.23 & 1.05 & 1.17 & 1.27 \\
\hline$V_{\theta, \max }^{*} / V_{\theta, \max }$ & 1.30 & 1.29 & 1.38 & 1.45 \\
\hline$r_{1}^{*} / r_{1}$ & 0.71 & - & 0.62 & - \\
\hline$r_{2}^{*} / r_{2}$ & - & 0.82 & - & 0.88 \\
\hline
\end{tabular}

Table 2. Effect of separation control on the outboard flap trailing vortices.

\begin{tabular}{|c|c|c|c|c|}
\hline & \multicolumn{2}{|c|}{ Outboard Vortex } & \multicolumn{2}{c|}{ Inboard Vortex } \\
\hline & 7-hole probe & Donaldson-Betz & 7-hole probe & Donaldson-Betz \\
\hline$\Delta \bar{y} / s(\%)$ & -2.32 & -2.07 & 2.62 & 0.93 \\
\hline$\Gamma^{* *} / \Gamma^{\prime}$ & 1.36 & 1.35 & 1.35 & 1.76 \\
\hline$V_{\theta, \max }^{*} / V_{\theta, \max }$ & 1.44 & 1.82 & 1.08 & 1.97 \\
\hline$r_{1}^{*} / r_{1}$ & 0.49 & - & 0.57 & - \\
\hline$r_{2}^{*} / r_{2}$ & - & 0.74 & - & 0.90 \\
\hline
\end{tabular}

Table 3a. Effect of segmented separation control on the outboard vortex trailing the outboard

\begin{tabular}{|c|c|c|c|c|}
\hline & \multicolumn{2}{|c|}{ Inboard Control } & \multicolumn{2}{|c|}{ Outboard Control } \\
\hline & 7-hole probe & Donaldson-Betz & 7-hole probe & Donaldson-Betz \\
\hline$\Delta \bar{y} / s(\%)$ & -0.34 & -0.48 & -2.50 & -2.21 \\
\hline$\Gamma^{\prime *} / \Gamma^{\prime}$ & 1.03 & 1.09 & 1.24 & 1.05 \\
\hline$V_{\theta, \text { max }}^{*} / V_{\theta, \text { max }}$ & 0.94 & 1.17 & 1.54 & 1.36 \\
\hline$r_{1}^{*} / r_{1}$ & 0.89 & - & 0.44 & - \\
\hline$r_{2}^{*} / r_{2}$ & - & 0.93 & - & 0.77 \\
\hline
\end{tabular}

Table 3b. Effect of segmented separation control on the inboard vortex trailing the outboard flap.

\begin{tabular}{|c|c|c|c|c|}
\hline & \multicolumn{2}{|c|}{ Inboard Control } & \multicolumn{2}{c|}{ Outboard Control } \\
\hline & 7 -hole probe & Donaldson-Betz & 7-hole probe & Donaldson-Betz \\
\hline$\Delta \bar{y} / s(\%)$ & 2.73 & 1.38 & 0.09 & -0.38 \\
\hline$\Gamma^{* *} / \Gamma^{\prime}$ & 1.32 & 1.38 & 1.01 & 1.19 \\
\hline$V_{\theta, \max }^{*} / V_{\theta, \max }$ & 1.25 & 1.61 & 0.85 & 1.18 \\
\hline$r_{1}^{*} / r_{1}$ & 0.41 & - & 0.91 & - \\
\hline$r_{2}^{*} / r_{2}$ & - & 0.86 & - & 1.01 \\
\hline
\end{tabular}




\section{Figures}

Fig. 1. Plan view schematic of the semi-span wing model, showing the layout and coordinate systems.

Fig. 2. Schematic illustrating the Donaldson-Betz vortex rollup method between the span-loading and the Trefftz plane (lower part), using experimental data (upper part), with and without separation control.

Fig. 3. (a) Inboard lift coefficient and (b) wing lift coefficient for two forcing amplitudes with inboard and outboard flaps deflected.

Fig. 4. Donaldson-Betz predictions of controlled vortex characteristics in dimensionless form: (a) strength; (b) centroid; (c) peak velocity; and (d) outer core radius, using experimentally determined span-loading.

Fig. 5. Changes to lift and moment coefficient as a function of forcing amplitude at two angles of attack and two forcing frequencies.

Fig. 6. Donaldson-Betz predictions of vortex characteristics as a function of forcing amplitude corresponding to the data in fig. 5.

Fig. 7. Spanwise flap trailing-edge pressure recovery for (a) inboard separation control and (b) outboard separation control for the $\left(\delta_{i}, \delta_{o}, \delta_{t}\right)=\left(20^{\circ}, 20^{\circ}, 0^{\circ}\right)$ configuration.

Fig. 8. Effect of passive and active, inboard and outboard, separation control on overall wing lift and moment coefficients.

Fig. 9. Span-loading for (a) passive and (b) active inboard and outboard control.

Fig. 10. Dimensionless vortex characteristics predicted using the Donaldson-Betz rollup relations, corresponding to the wing lift and moment coefficients shown in fig. 8.

Fig. 11. Seven-hole probe measurements of axial vorticity and in-plane velocity for the scenarios: (a) passive-inboard control; (b) passive outboard control; (c) active-inboard control; (d) active outboard control $(x / c=2)$.

Fig. 12. Seven-hole probe measurements of axial velocity for the scenarios: (a) passive-inboard control; (b) passive outboard control; (c) active-inboard control; (d) active outboard control $(x / c=2)$.

Fig. 13. Vortex map in the $(y, z)$ plane, illustrating the two-dimensional vortex excursion resulting from separation control $(x / c=2)$. 
Fig. 14. Seven-hole probe measurements of axial vorticity for (a) baseline and (b) control cases in the wake of the outboard flap $(x / c=2)$.

Fig. 15. Seven-hole probe measurements of axial velocity for (a) baseline and (b) control cases in the wake of the outboard flap $(x / c=2)$.

Fig. 16. Lift and moment coefficients corresponding to perturbations introduced on the inboard and outboard halves of the outboard flap.

Fig. 17. Span-loading and trailing-edge pressure recovery for control introduced on the inboard and outboard halves of the outboard flap.

Fig. 18. Seven-hole probe measurements of axial vorticity and in-plane velocity for: (a) outboard and (b) inboard control cases $(x / c=2)$.

Fig. 19. Upper surface phase-averaged unsteady pressure coefficients at $f_{w}=4 \mathrm{~Hz}$ responding dynamically to periodic separation and attachment of the boundary layer.

Fig. 20. Maximum and minimum pressure coefficients as a function of wavelength: (a) at the trailing-edge and (b) at the leading-edge. 


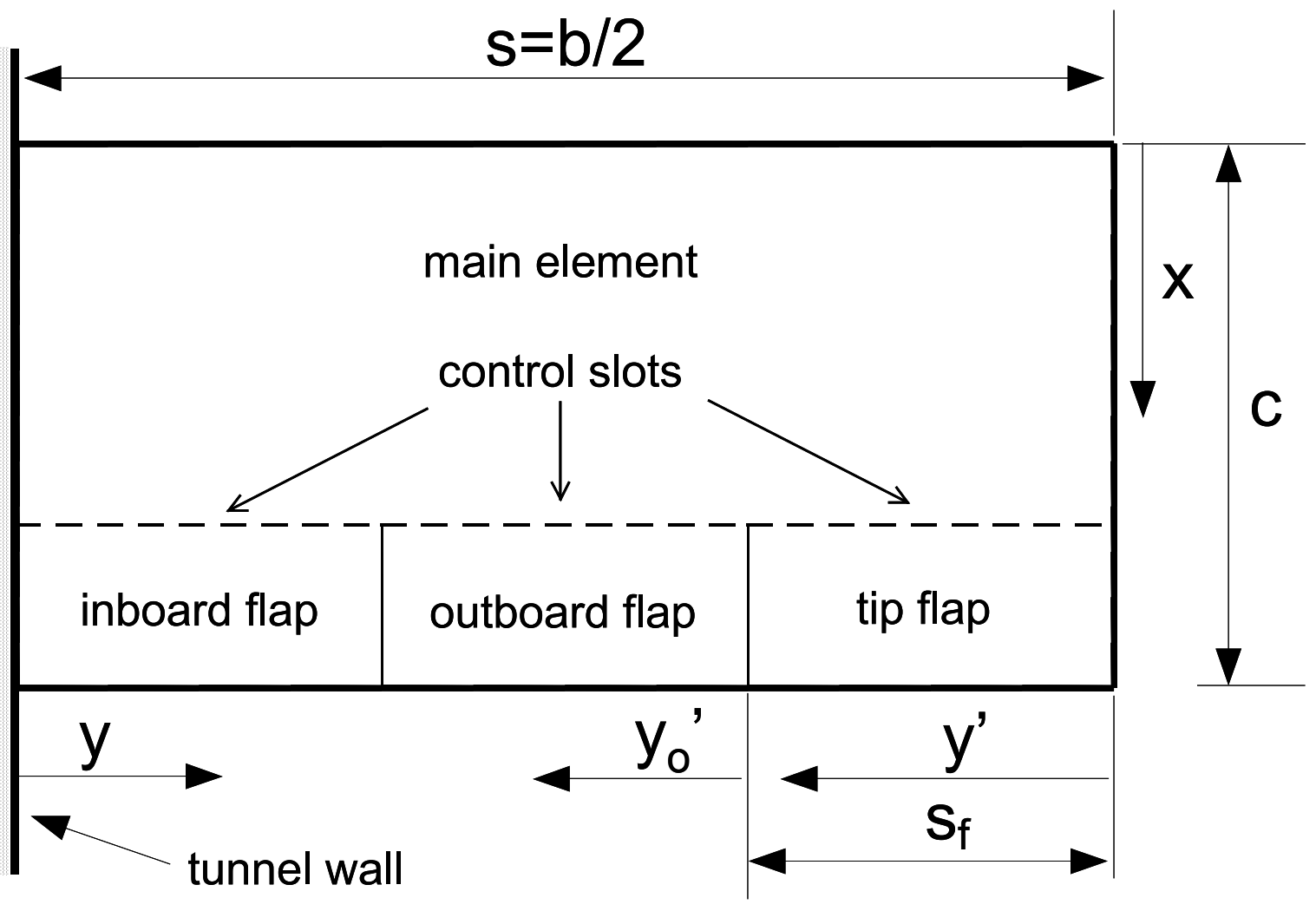

1 


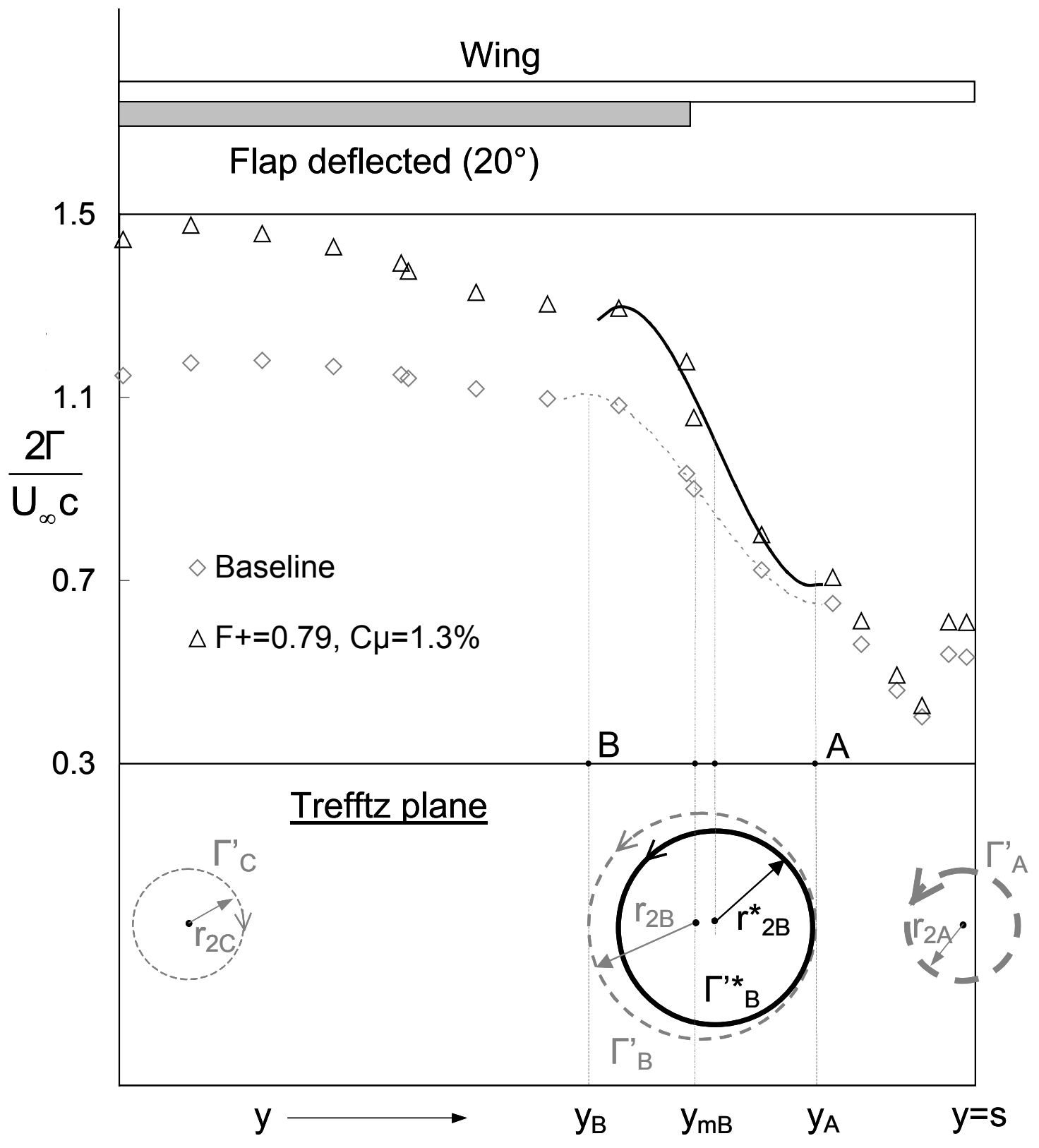



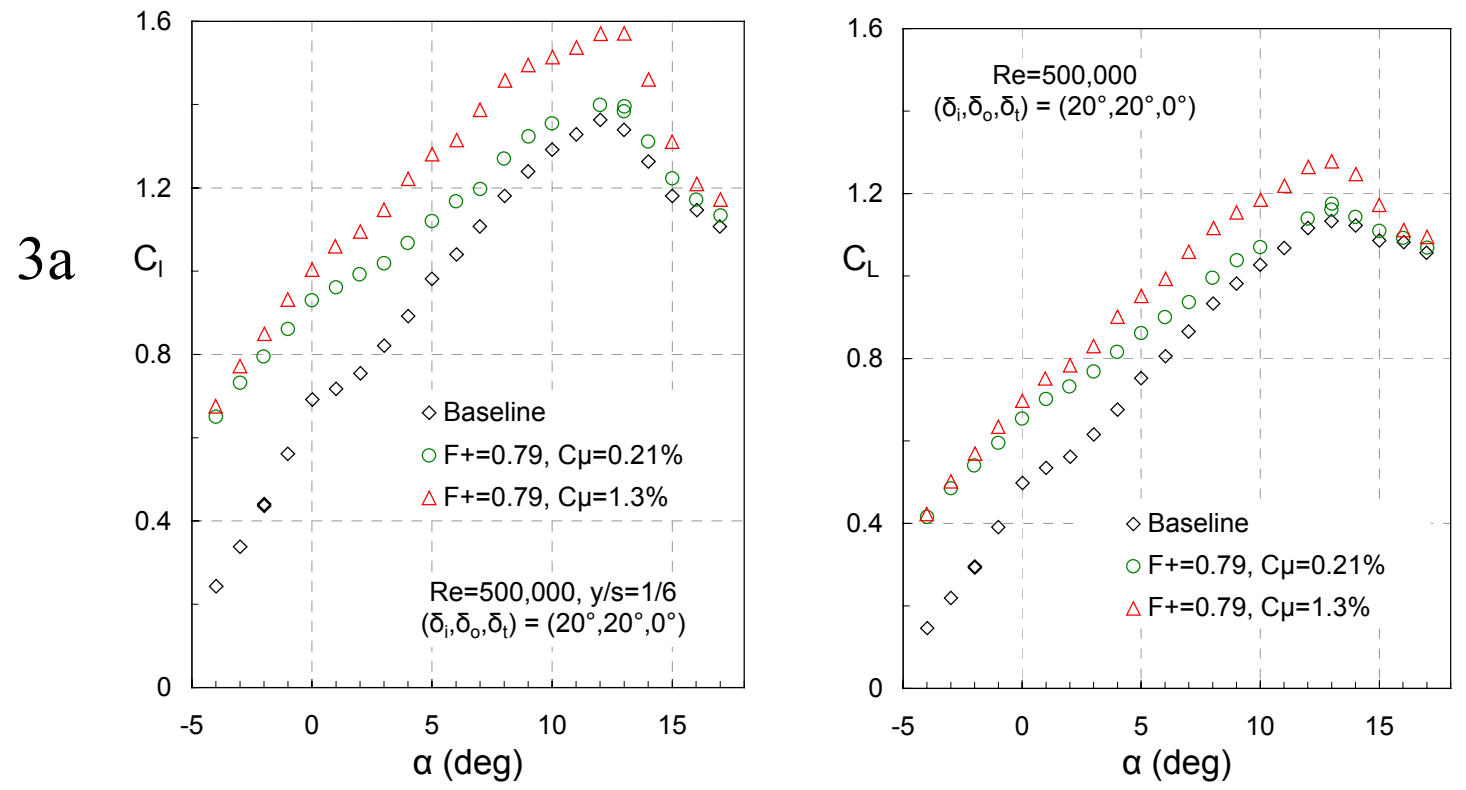

$3 b$
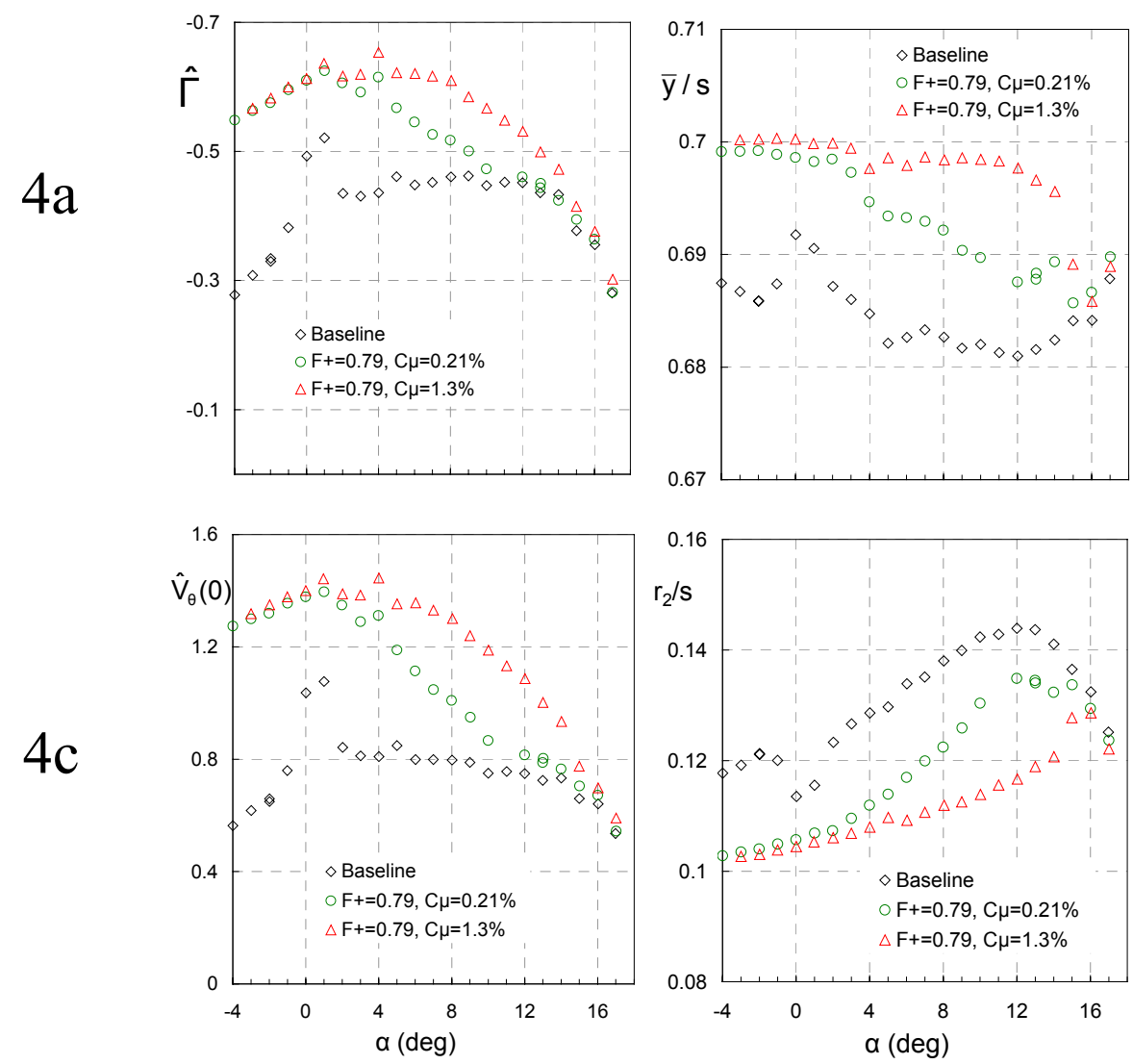


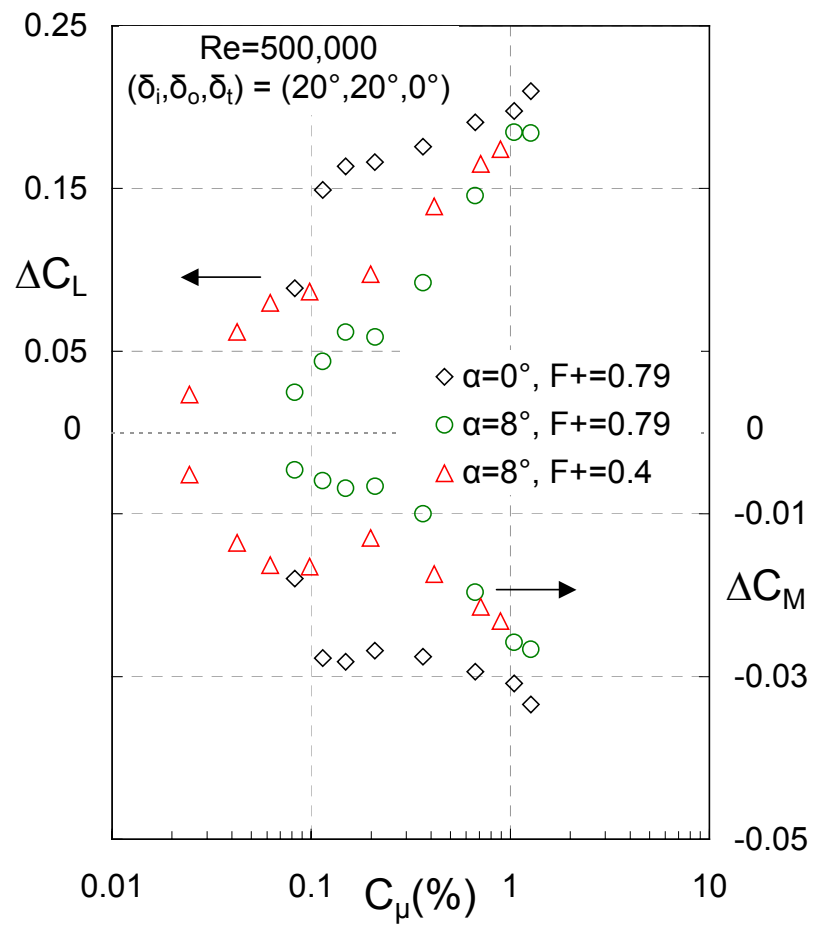

$6 a$
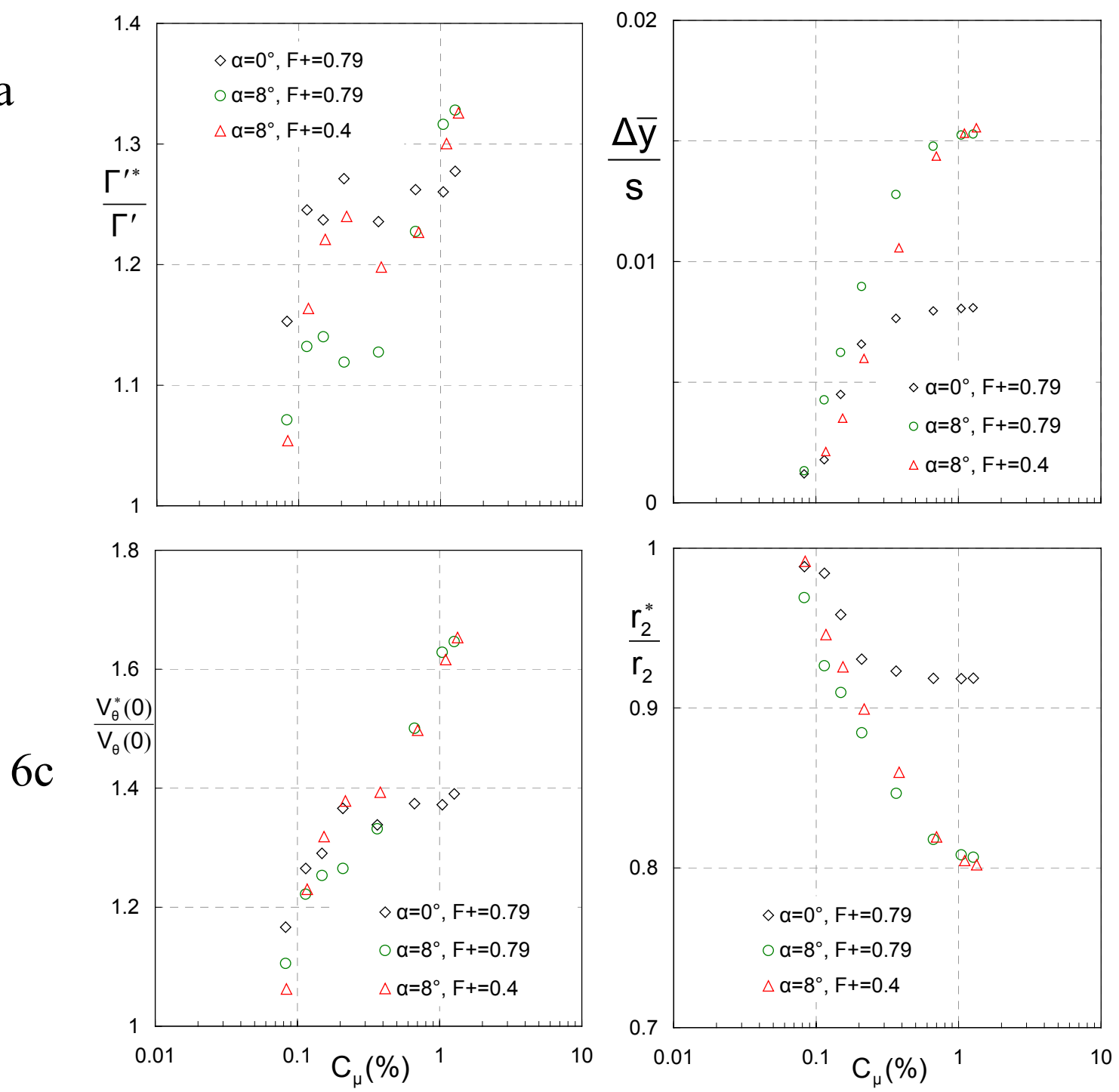

$6 b$ 


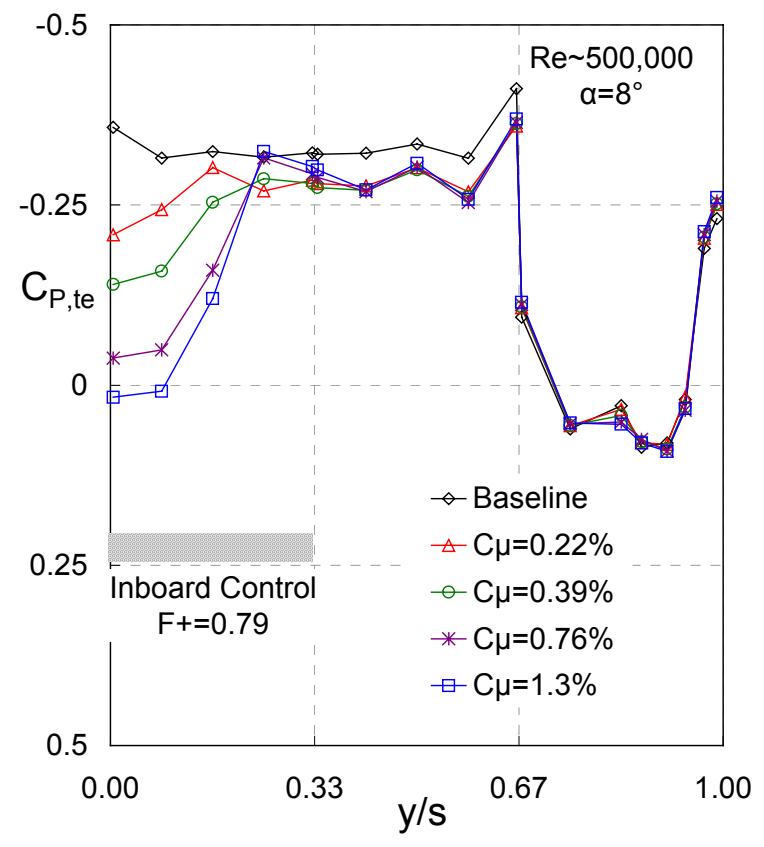

$7 \mathrm{a}$

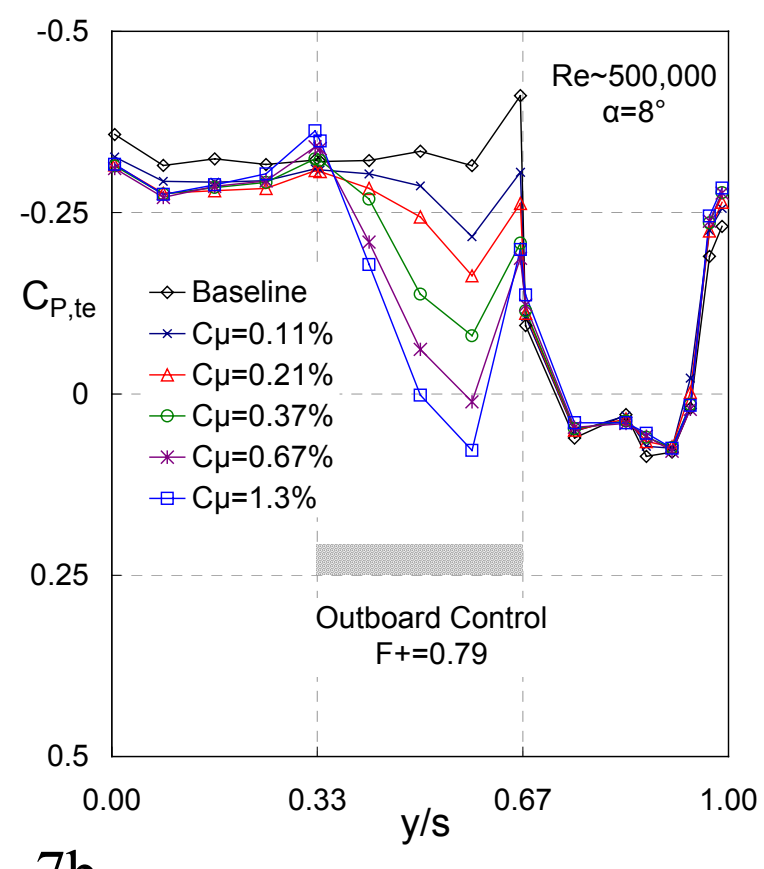

$7 \mathrm{~b}$

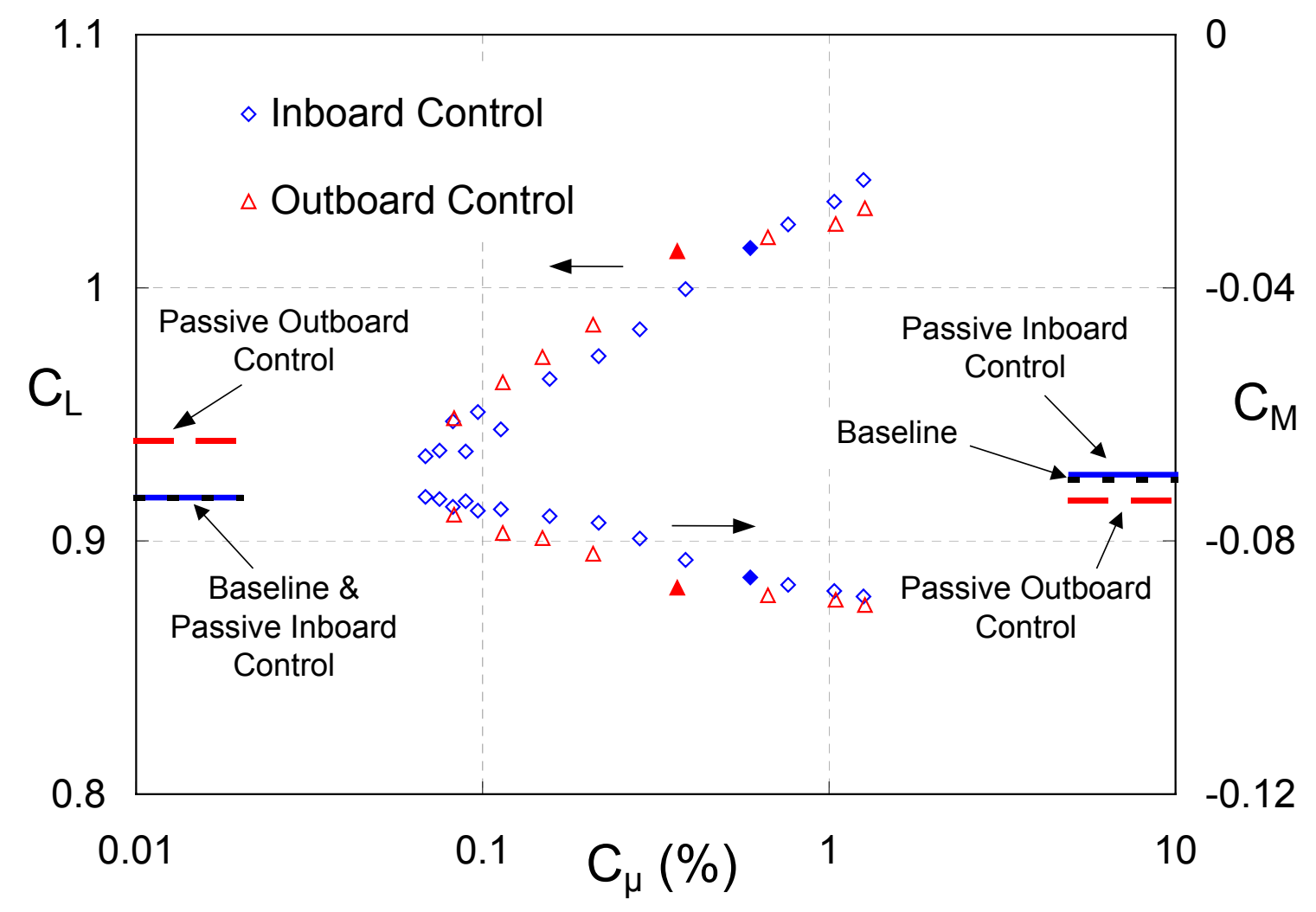



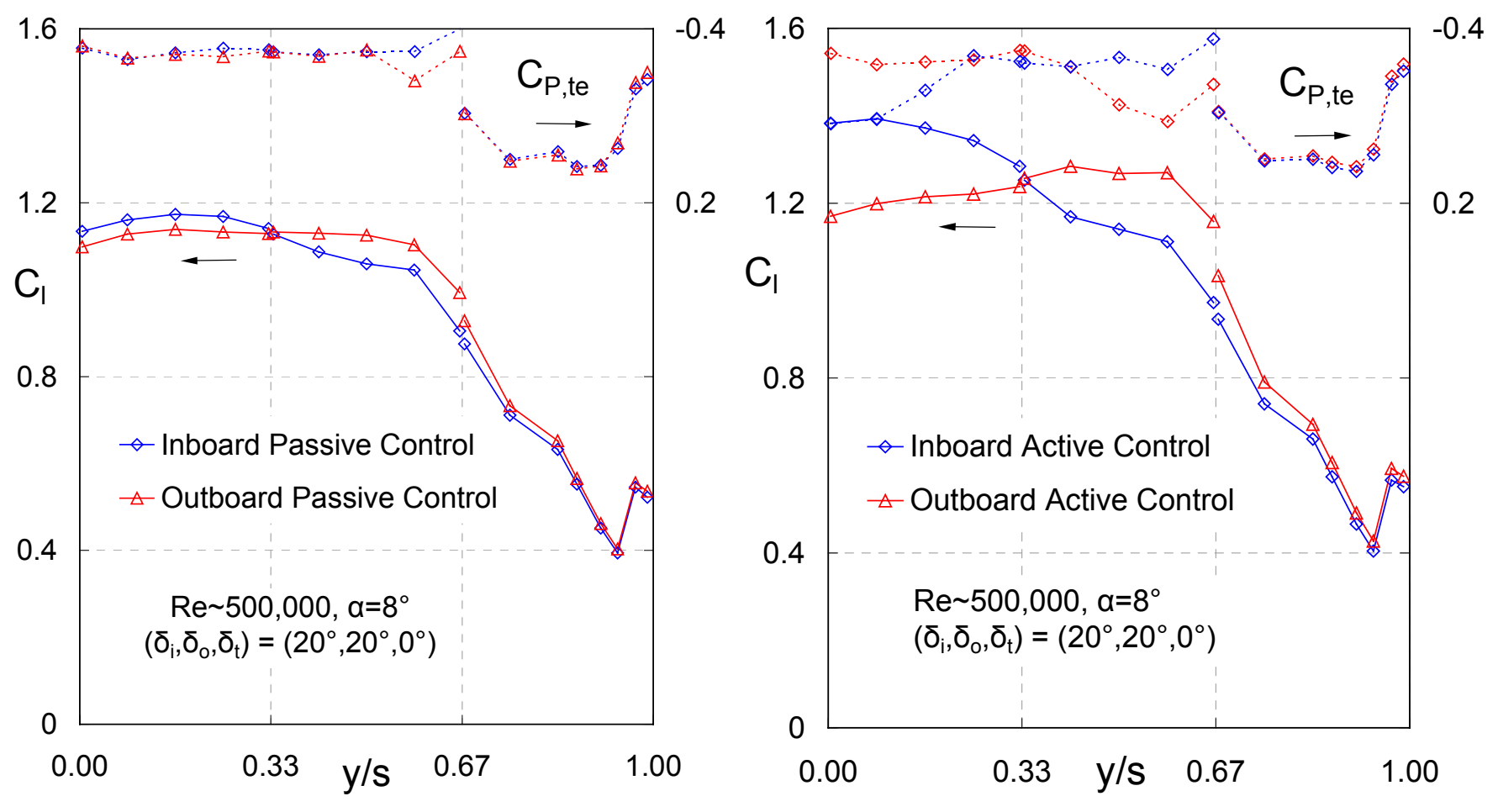

9a,b 

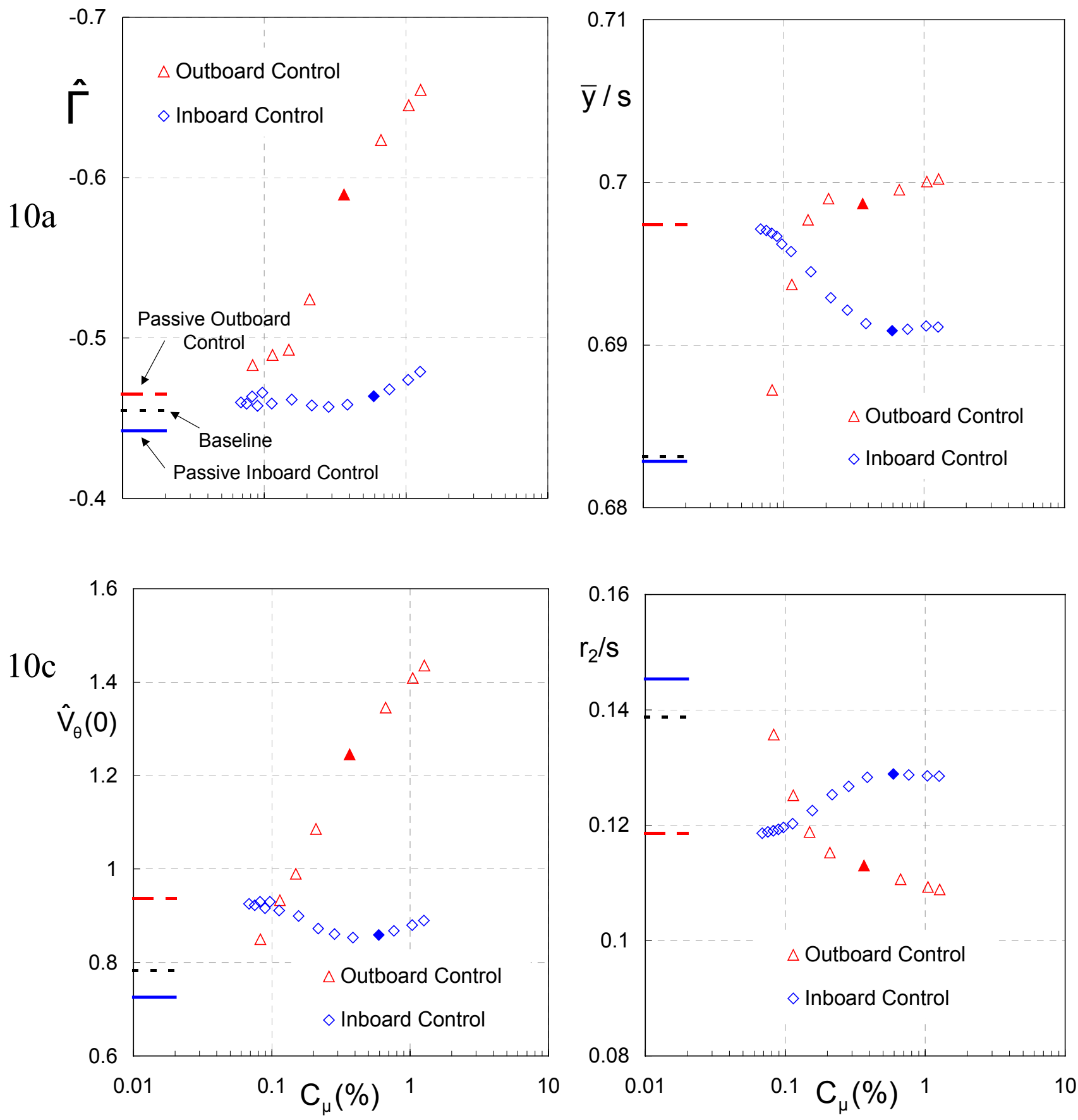

$10 b$

$10 \mathrm{~d}$ 


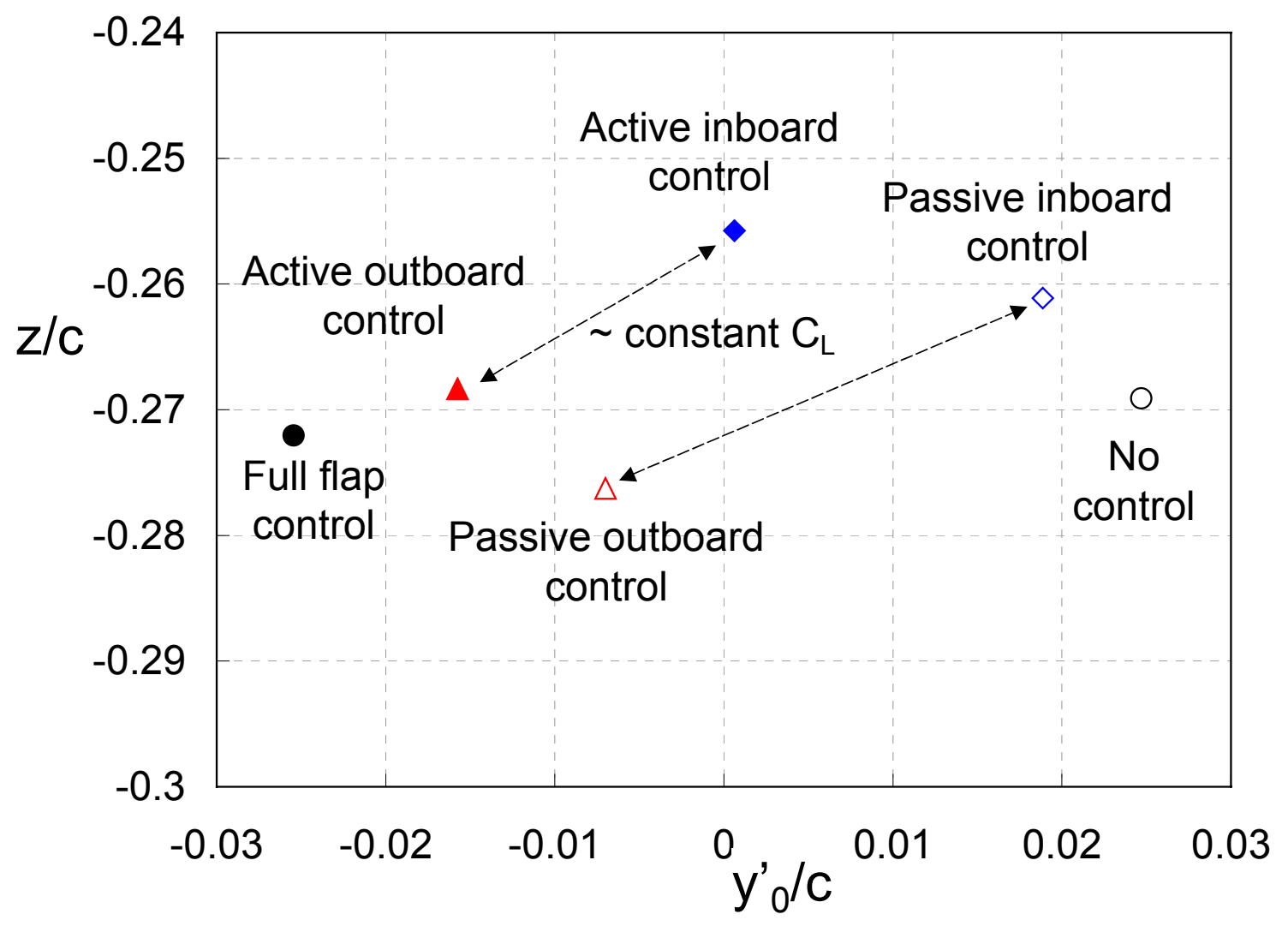

13 

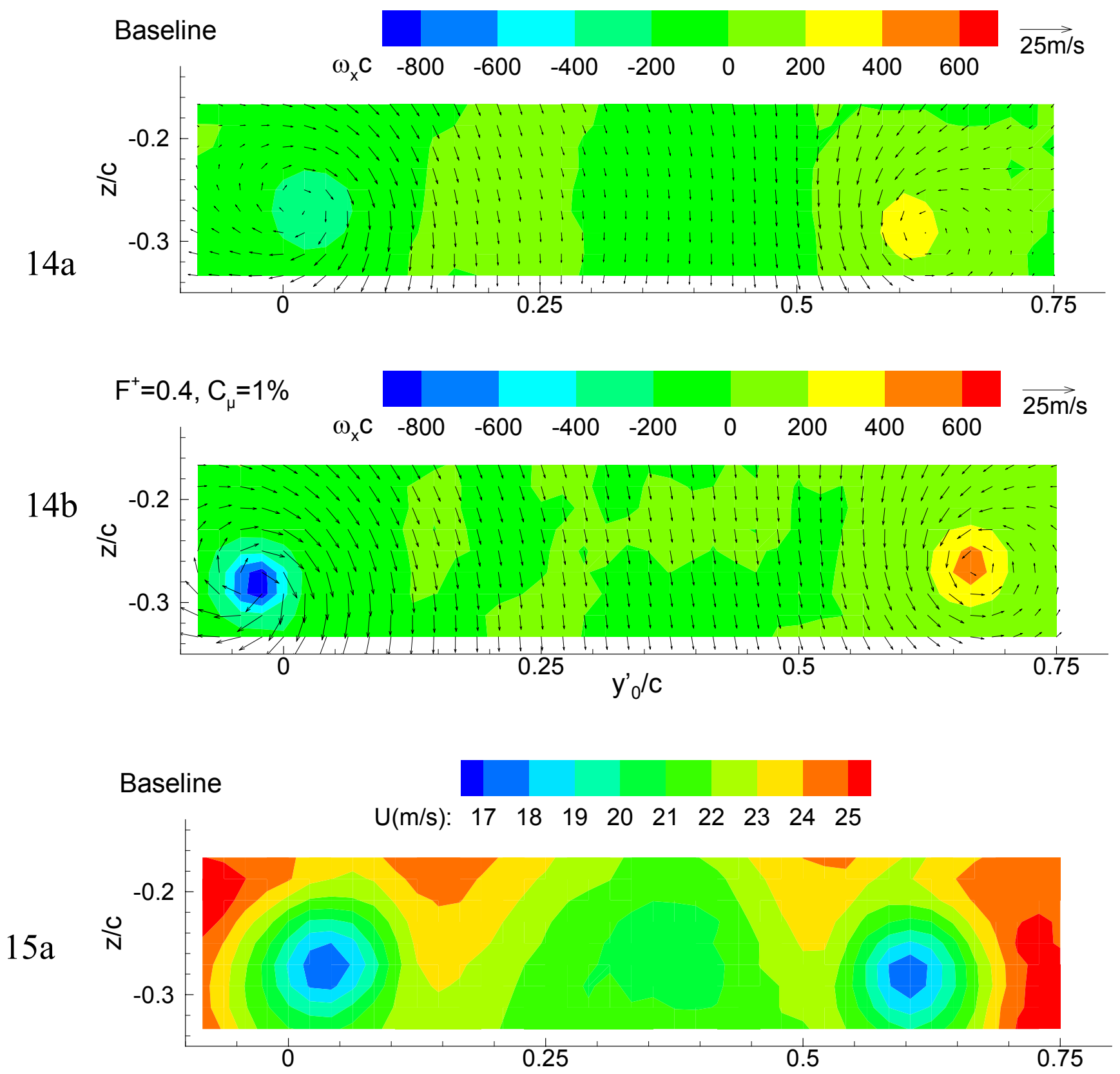

$15 b$

$$
F^{+}=0.4, C_{\mu}=1 \%
$$

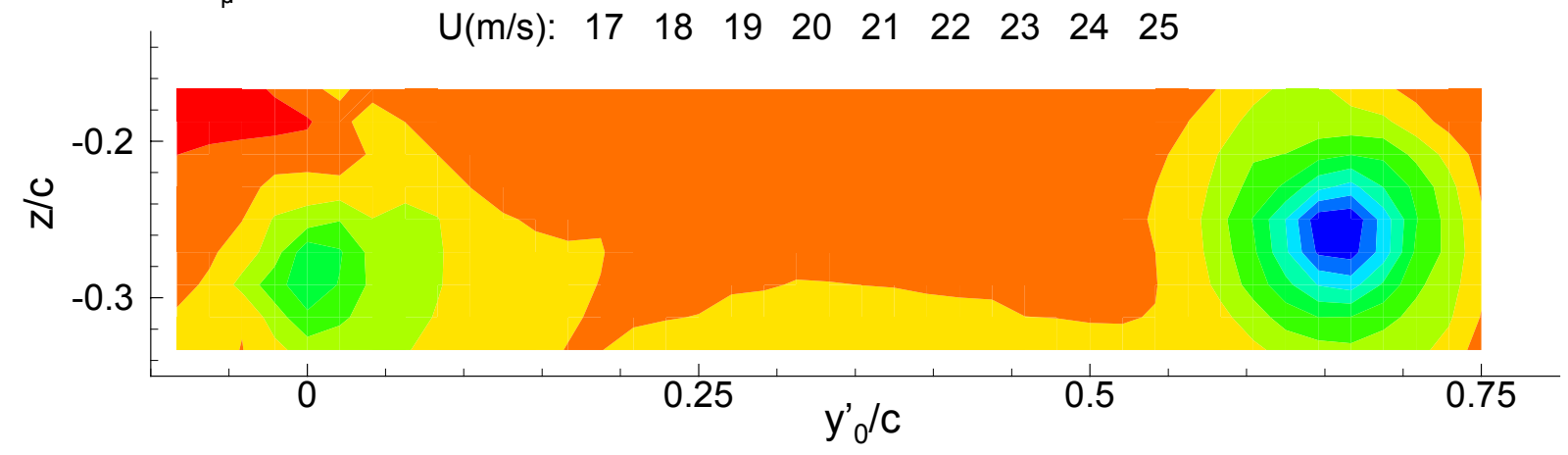




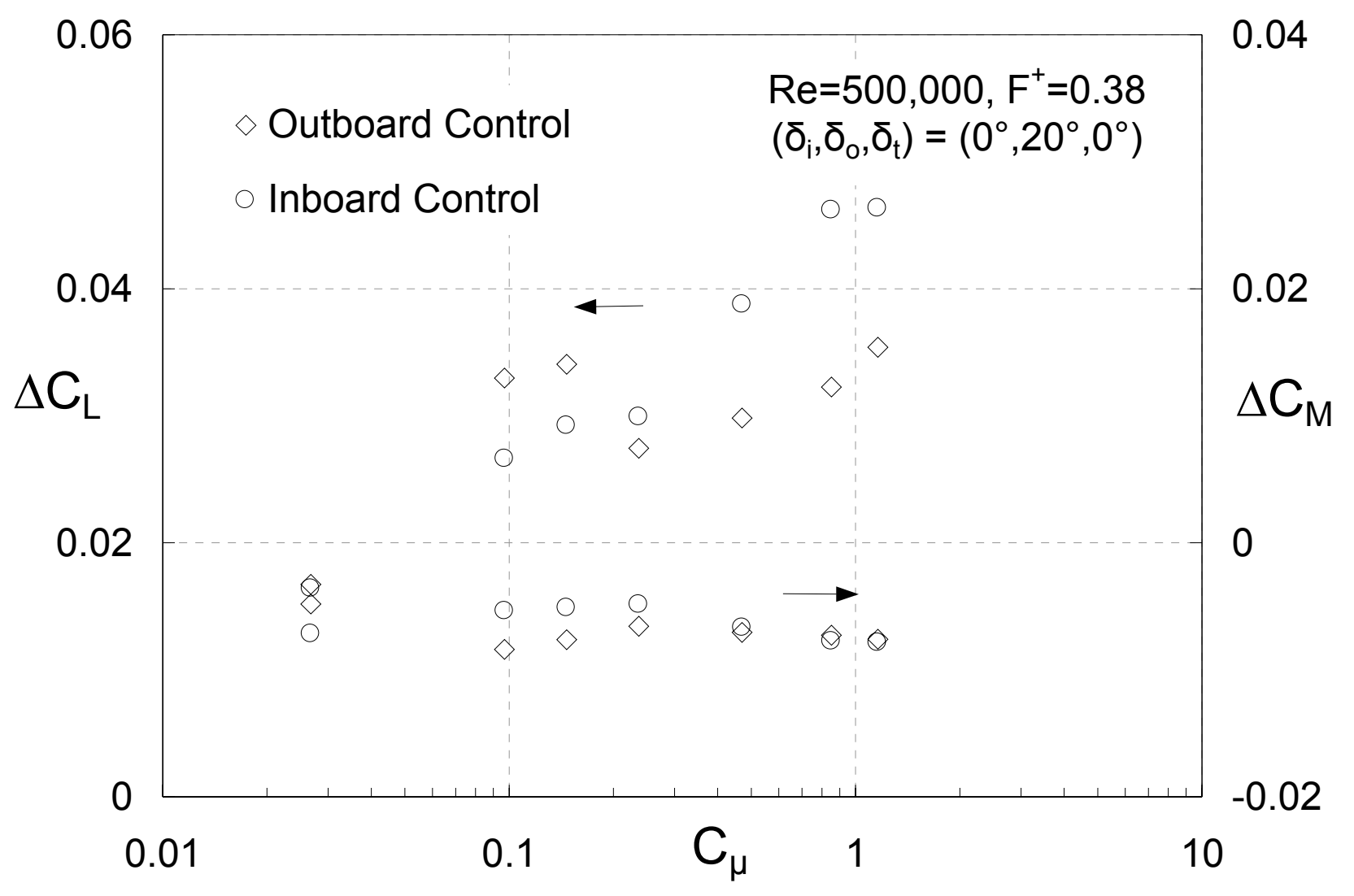

16 


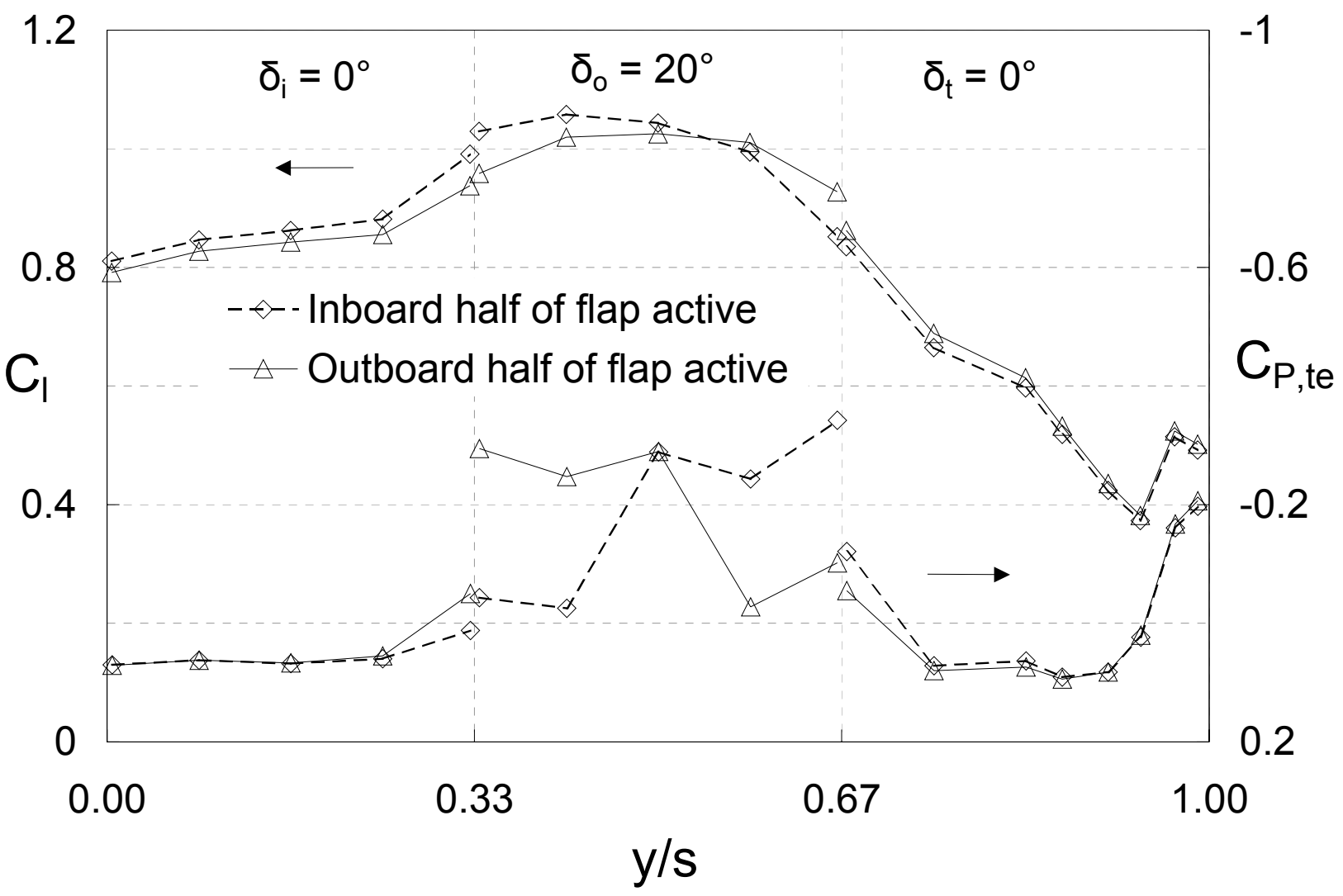

17 
Outboard Control

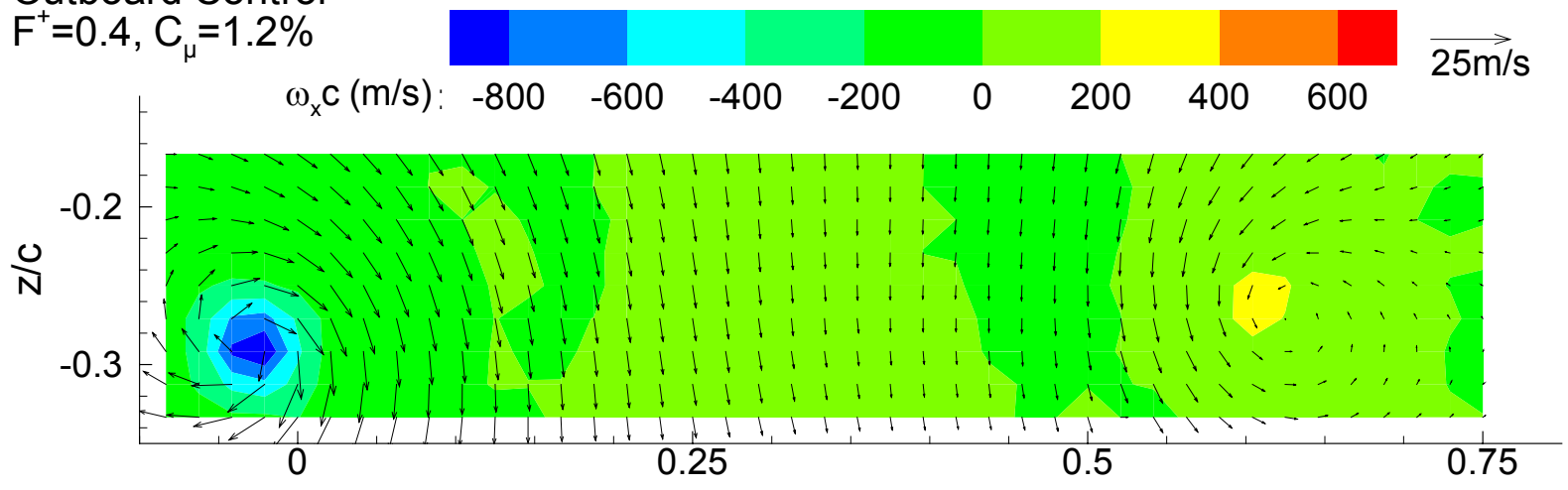

Inboard Control

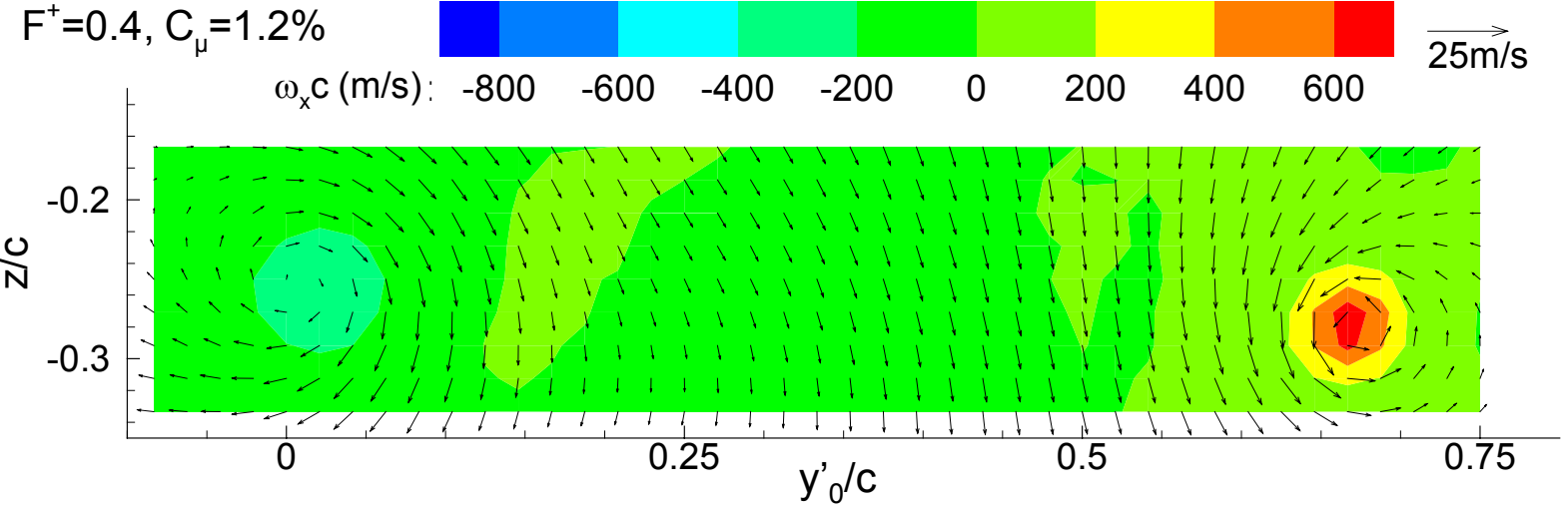

$18 \mathrm{a}, \mathrm{b}$ 


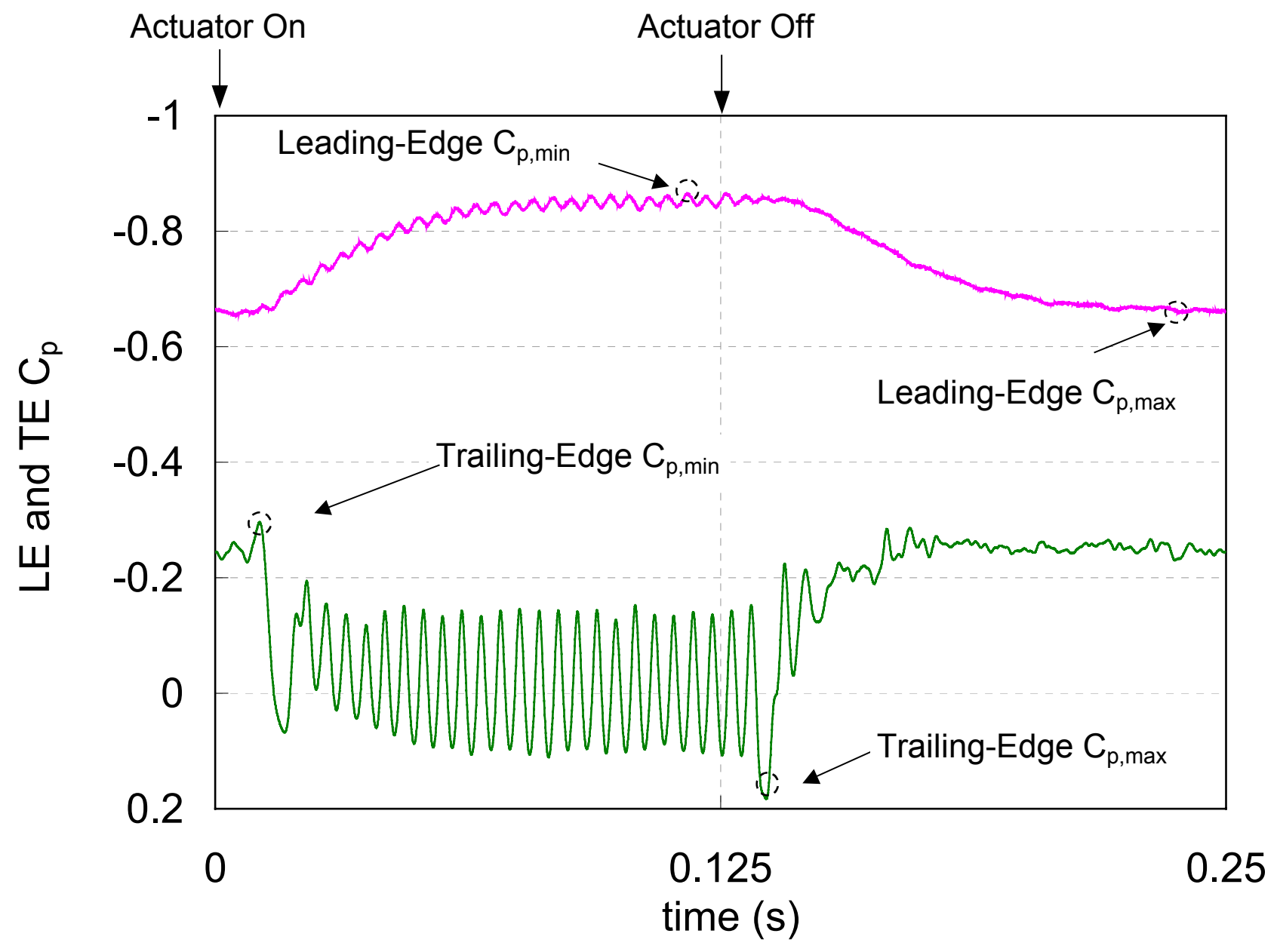

19 
